\title{
Coastal vulnerability assessment of Puducherry coast, India, using the analytical hierarchical process
}

\author{
R. Mani Murali ${ }^{1}$, M. Ankita ${ }^{1}$, S. Amrita ${ }^{2}$, and P. Vethamony ${ }^{1}$ \\ ${ }^{1}$ CSIR-National Institute of Oceanography, Dona Paula, Goa, India \\ ${ }^{2}$ Pondicherry University, Puducherry, India \\ Correspondence to: R. Mani Murali (mmurali@nio.org) \\ Received: 1 February 2013 - Published in Nat. Hazards Earth Syst. Sci. Discuss.: 19 March 2013 \\ Revised: 9 November 2013 - Accepted: 14 November 2013 - Published: 16 December 2013
}

\begin{abstract}
As a consequence of change in global climate, an increased frequency of natural hazards such as storm surges, tsunamis and cyclones, is predicted to have dramatic affects on the coastal communities and ecosystems by virtue of the devastation they cause during and after their occurrence. The tsunami of December 2004 and the Thane cyclone of 2011 caused extensive human and economic losses along the coastline of Puducherry and Tamil Nadu. The devastation caused by these events highlighted the need for vulnerability assessment to ensure better understanding of the elements causing different hazards and to consequently minimize the after- effects of the future events. This paper demonstrates an analytical hierarchical process (AHP)-based approach to coastal vulnerability studies as an improvement to the existing methodologies for vulnerability assessment. The paper also encourages the inclusion of socio-economic parameters along with the physical parameters to calculate the coastal vulnerability index using AHP-derived weights. Seven physical-geological parameters (slope, geomorphology, elevation, shoreline change, sea level rise, significant wave height and tidal range) and four socio-economic factors (population, land use/land cover (LU/LC), roads and location of tourist areas) are considered to measure the physical vulnerability index (PVI) as well as the socio-economic vulnerability index (SVI) of the Puducherry coast. Based on the weights and scores derived using AHP, vulnerability maps are prepared to demarcate areas with very low, medium and high vulnerability. A combination of PVI and SVI values are further utilized to compute the coastal vulnerability index (CVI). Finally, the various coastal segments are grouped into the 3 vulnerability classes to obtain the coastal vulnerability map. The entire coastal extent between Muthiapet
\end{abstract}

and Kirumampakkam as well as the northern part of Kalapet is designated as the high vulnerability zone, which constitutes $50 \%$ of the coastline. The region between the southern coastal extent of Kalapet and Lawspet is the medium vulnerability zone and the remaining $25 \%$ is the low vulnerability zone. The results obtained enable the identification and prioritization of the more vulnerable areas of the region in order to further assist the government and the residing coastal communities in better coastal management and conservation.

\section{Introduction}

In light of the disproportionate climate change, the coastal areas constitute the most productive, yet vulnerable, ecosystems in the world. These coastal belts often prove to be the hot spots of severe impacts associated with permanent inundation of low-lying areas, increased flooding due to extreme weather events like storm surges and tsunamis, greater erosion rates affecting beaches and cliffs, and devastation due to calamities like cyclones (Nicholls and Cazenave, 2010; EC, 2005; EEA, 2006; Klein et al., 2003). The greenhouse effect (caused by greenhouse gases released due to pollution) leading to global warming has severe implications on the regions bordering the oceans. According to a recently projected estimate, the global climate will warm by around $0.2{ }^{\circ} \mathrm{C}$ per decade in the next $20 \mathrm{yr}$ (IPCC, 2007). By the end of this century, the sea level may rise by as much as $1.5 \mathrm{~m}$ (Strohecker, 2008) due to warming water, melting glaciers and disappearing ice sheets. The accelerated sea level rise and possible increase in the intensity and frequency of cyclones (Unnikrishnan et al., 2006) related to increased sea surface temperature, 
will cause serious ramifications such as flooding, coastal erosion and shoreline retreat (Pye and Blott, 2006). Such projections are adversely linked to sustainable coastal management as they lead to geomorphic changes along the coastline as well as damage to coastal ecosystems and resources.

In addition to threats due to natural hazards, these regions also face immense population and developmental pressures. Creel (2004) reports that approximately half of the world's population live within $200 \mathrm{~km}$ of a coastline. Development affects natural coastal functioning, in particular the equilibrium between terrestrial shoreline environments - the beach and near-shore bathymetry. In extreme cases, this leads to the loss of coastal lands making them highly susceptible to the impacts of sea level rise, coastal erosion, extreme weather and other coastal hazards (O'Connor et al., 2009). From the developing country prospective, the increase in number and intensity of natural hazards due to climate change and their potential impact on climate sensitive sectors, throws light on the need to find alternatives to deal with these events more effectively before, during and after their occurrence.

The need for local scale assessments is further highlighted by the several disaster events (McFadden et al., 2007) that take place frequently along the coasts of countries like India, Bangladesh or Thailand. In recognition of these risks, there is a need to develop methodologies to assess coastal vulnerability to ensure efficient hazard management and mitigation (Cooper and Mckenna, 2008; McFadden et al., 2007).

\subsection{Coastal vulnerability}

The definition of vulnerability in the climate change context falls into two main categories: (i) potential damage caused by the natural hazard (Jones and Boer, 2003), and (ii) the inherent existing state of the system before it encounters an event (Allen, 2003). The IPCC fourth assessment report (2007) specifies vulnerability to be a function of the character, magnitude, rate of climate variation to which a system is exposed, its sensitivity and its adaptive capacity. However, in this framework vulnerability can be understood to be a composition of multiple interacting factors emerging from the social, economic and environmental spheres of an exposure unit (Turner et al., 2003; Birkmann, 2006). Thus, vulnerability is often expressed in the form of quantitative indices, and this is considered as a key step towards vulnerability assessment which is furthermore essential for disaster prevention, management and mitigation (Romieu et al., 2010). Indices are applied for various scientific objectives, such as for identifying cause-effect relationships, for mapping and ranking in order to compare vulnerability across regions and for realistic assessment of risks (Füssel and Klein, 2006), as they not only provide consistent and rapid characterizations but also provide them at many spatial scales (local to global).

One of the most initial attempts to formalize a coastal vulnerability index, particularly for sea level rise, was developed by Gornitz and Kanciruk (1989) for the United
States. Coastal slope, geomorphology, relative sea level rise rate, shoreline change rate, mean tidal range and mean wave height were the main parameters used by Thieler and Hammer-Klose (1999) for assessment of coastal vulnerability of the US Atlantic coast. The coastal vulnerability index (CVI) of the Golden Gate National Area to sea level rise was assessed by Pendleton et al. (2005). These assessments are generally based on remotely sensed data as an input and processed by means of GIS methodology. This method is particularly useful as it does not rely on detailed, precise or longterm data, which when working at a regional scale is rarely available and costly to produce (Bryan et al., 2001). However, a major inadequacy in the case of most vulnerability assessments is that they focus only on the physical characteristics of vulnerability, with little inclusion of economic and ecological aspects (Boruff et al., 2005). In the Indian context, several vulnerability studies have been taken for the east coast as well as west coast for sea level rise using physical variables as an input to the Coastal Vulnerability Index. Shoreline movement (Mani Murali et al., 2009) and run up as well as inundation limits (Jayakumar et al., 2005) were studied along parts of east coast of India for anthropogenic and tsunami studies, respectively. Dwarakish et al. (2009) calculated CVI for the coastal zone of Udupi, Karnataka from shoreline change, rate of sea level change, coastal slope, tidal range, coastal geomorphology. CVI for Orissa was assessed by Kumar et al. (2010) using an additional parameter of tsunami run-up. The vulnerability to multiple hazard scenarios along the coast of Cuddalore-Villupuram was assessed by Mahendra et al. (2011) by incorporating storm surge parameters along with other physical factors. Kumar et al. (2012) did a vulnerability assessment of the Chennai coast using geo-spatial technologies. In a majority of these studies the CVI is expressed as the square root of the product of the ranking factors divided by the number of parameters considered (Thieler and Hammer-Klose, 2000). However, Vittal Hegde and Radhakrishnan Reju (2007) used the sum of the value of each variable divided by the number of variables. Later, Nageswara Rao et al. (2008) calculated CVI by taking the summation of the variables considered with the ranks of each multiplied by their corresponding weights on the Andhra Pradesh coast.

The limitation in these studies is that the weights are deduced using an individual's discretion, moreover socioeconomic factors are not taken into consideration. However, Adger (1996) suggests that social vulnerability is a key dimension that shifts emphasis onto the underlying rather than proximate cause of vulnerability and hence is an important constitution of vulnerability. Boruff et al. (2005) computed the overall coastal social vulnerability score (CSoVI) by considering socio-economic variables in a principal component analysis. Willroth et al. (2012) studied the socio-economic vulnerability of coastal communities in southern Thailand and also discussed that social networks played a crucial role in coping with the disaster. Thus, it is imperative to integrate 
socio-economic data in these kinds of studies to judge the vulnerability associated with the people living in the coastal areas facing pressure due to coastal hazards. This is because these disasters do not become catastrophes until human lives are affected and hence the addition is essential for overall understanding of the vulnerability of a region.

The main aim of this paper is therefore to present an analytical hierarchical process (AHP) based Coastal vulnerability Index (CVI) taking both physical-geological (PVI) and socio-economic parameters (SVI) into consideration.

\subsection{The AHP process and application in coastal vulnerability mapping}

The AHP method proposed by Saaty (1977) and Saaty and Vargas (1991), provides a better understanding of the complex decisions by decomposing the problem into a hierarchical structure. AHP enables us to arrive at a scale of preference amongst the available alternatives by employing a pairwise comparison procedure between the decision elements and by ranking them according to their relative importance (Ju et al., 2012). We have suggested this methodology as an improvement to the traditional CVI studies as we believe that AHP-deduced weights provide better estimations. AHP has several advantages over these traditional methodologies; firstly, it takes into consideration expert opinions when the data involved are inconsistent or insufficient. This has immense significance, especially in the case of mapping coastal vulnerability as the data is highly heterogeneous in terms of its scale, temporal resolution, etc. The ability of AHP to integrate expert opinion as well as convert qualitative information to quantitative weights makes it very beneficial to coastal vulnerability studies. Secondly, the pair-wise comparison allows the prioritization of various parameters relative to each other. This is important in the case of regional studies, where one parameter may be more dominant in one region than the other. Also, it is always desirable to use logically derived weights in the case of ranking studies (e.g. AHP derived) rather than those allocated arbitrarily. Finally, the test of consistency in the case of AHP helps to check the effectiveness of measurements and judgments, which provide a certain degree of reliability to the study in comparison with random weights.

AHP has been used as a decision-making tool in several studies relating to landslide hazard zonation, flood mapping and soil erosion hazard mapping (Phukon et al., 2012; Bhatt et al., 2010; Sinha et al., 2008; Rahman et al., 2009). However, its use for coastal vulnerability has been very limited. Chang et al. (2012) used AHP to prioritize the protection of the Miaoli coast, Taiwan. Yin et al. (2012) and Ozyurt et al. (2011) have made an assessment of the coastal vulnerability to sea level rise for the Chinese coast and Turkish coast, respectively. A recent study (Le Cozannet et al., 2013) dealing with AHP and coastal vulnerability discusses the nuances (advantages, disadvantages and uncertainties) of this approach extensively. Apart from these applications, the use of AHP is rare for coastal studies and none has been reported in the case of Indian subcontinent.

Therefore, the present analysis includes identification and relative ranking (AHP based) of vulnerable units based on geological-physical and socio-economic parameters, demarcation of the priority regions in order to aid in regional assessment and to provide suitable information for planning preventive measures. The region chosen for this assessment is the Puducherry coast as, after the devastation caused by cyclone Thane, it is considered highly vulnerable to natural disasters. Moreover, this particular shoreline is famous for being erodible in nature due to both natural as well as anthropogenic reasons.

\section{Study region}

The study area (Fig. 1) is the region along Puducherry situated on the east coast of India, between $79.87^{\circ} \mathrm{E}$ and $79.79^{\circ} \mathrm{E}$ longitudes and $12.05^{\circ} \mathrm{N}$ and $11.75^{\circ} \mathrm{N}$ latitudes. The union territory of Puducherry consists of four unconnected regions of Puducherry, Karaikal and Yanam which lie on the Bay of Bengal and Mahe which lies on the Arabian Sea. The Puducherry region considered in this study is an enclave of the Tamil Nadu state of India. There are two rivers draining this region (1) the Gingee river, which traverses the region diagonally from north-west to south-east, and (2) the Ponnaiyar (Penniyar) river, which forms the southern border of the region. The three major physiographic units generally observed are coastal plain (younger and older), alluvial plain and uplands (National Assessment of shoreline change: Puducherry coast, 2011, Ramesh et al., 2011). The entire area, except the northeastern corner, is mostly covered by sedimentary formations ranging in age from cretaceous to recent. The physiographic map of the area presents more or less a flat land with an average elevation of about $15 \mathrm{~m}$ a.m.s.l. Puducherry's average elevation is at sea level, and a number of sea inlets, referred to as "backwaters" are present. This coastal zone is largely low-lying with a gentle slope, thus making it highly vulnerable to inundation. The coastal erosion or accretion takes place as a part of a natural cycle and there is a balance, annually and seasonally between accretion and erosion. The Bay of Bengal is one of the six regions in the world where severe tropical cyclones originate, and this area in particular was one of the worst hit during 2004 Indian Ocean tsunami. In 2011, a very severe cyclonic storm "Thane" with a wind speed of $140 \mathrm{~km} \mathrm{~h}^{-1}$ ( $85 \mathrm{mph}$ ) to $150 \mathrm{~km} \mathrm{~h}^{-1}(90 \mathrm{mph})$ crossed this study region. Thane made landfall early on 30 December 2011, on the north Tamil Nadu coast between Cuddalore and Puducherry and resulted in an extensive loss of life and damage of property. Thus, the susceptibility of this region to natural hazards and their devastating effects highlights the need for a vulnerability assessment to assist the administration (state and district level) in better disaster planning and mitigation. 

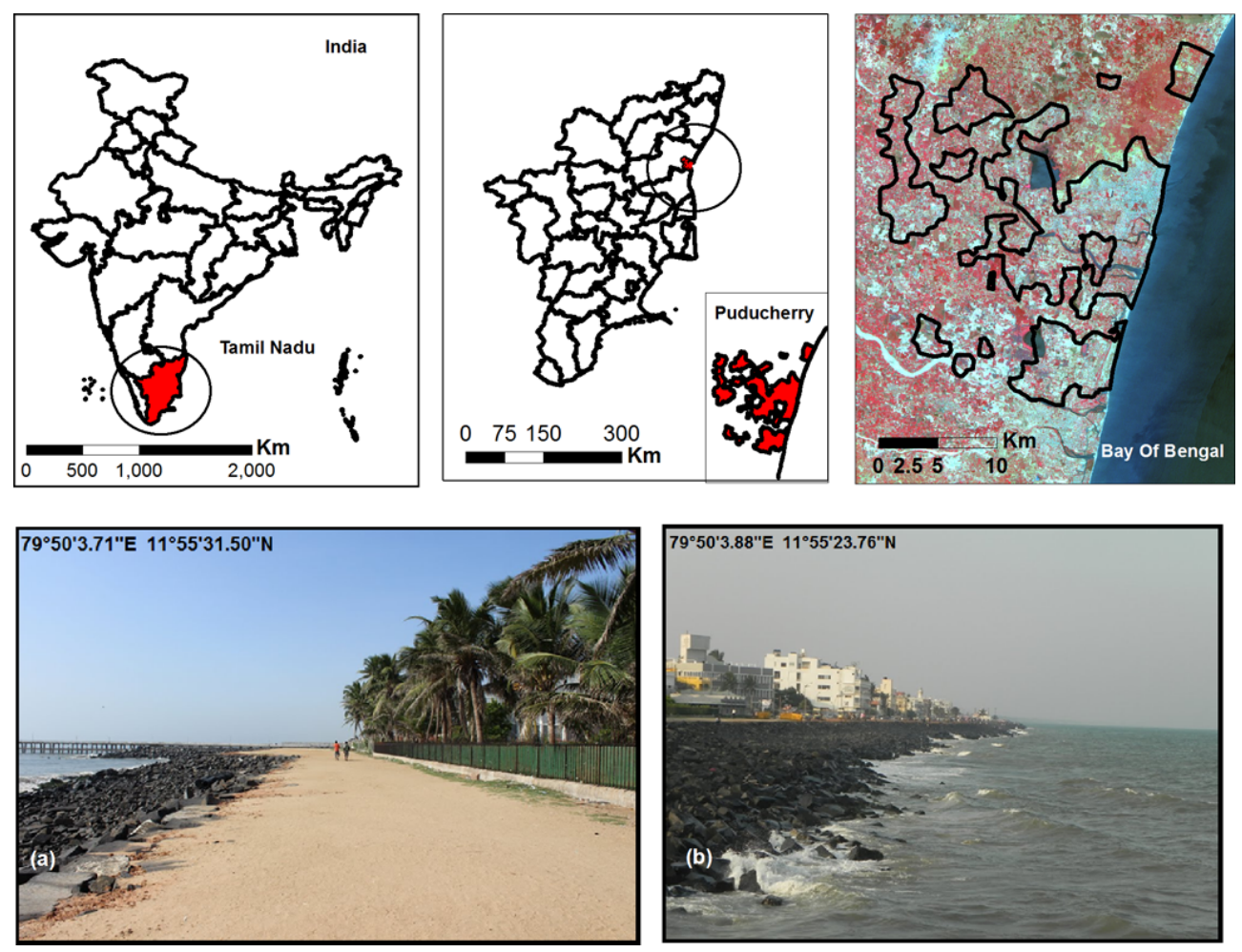

Fig. 1. Map showing location of study area. (a) This photo was taken near to the duplex park and compound wall of the park guest house complex. Rock boulders are seen to arrest the coastal erosion. This place is close to the highly populated urban area. (b) This photo shows the absence of beach, coastal road along the coastline, urban development, etc. It is just north of Puducherry harbour jetty.

\section{Methods and procedures}

According to Füssel and Klein (2006) vulnerability to climate change is the degree to which geophysical, biological and socio-economic systems are susceptible to, and unable to cope with, adverse impacts of climate change. Vulnerability assessments should shift their focus from quantifying the vulnerability of a place to rather evaluating the vulnerability of selected parameters of concern and to specific sets (Luers et al., 2003). From this perspective, although not quantitatively, qualitatively the relative exposure of the different coastal environments to natural hazards can be studied using information pertaining to various physical as well as geological aspects of the shoreline as an input to estimate the physical vulnerability index (PVI). Klein et al. (2003) suggested that this approach (indices) is desirable as it combines the coastal system's susceptibility to change with its natural capacity to adjust to dynamic environmental conditions and yields a relative estimate of the system's vulnerability to hazardous events. The present approach is comparable to that used by Pendleton et al. (2005) and Thieler and Hammer-Klose $(1999,2000)$ in terms of the usage of indices for estimation of vulnerability. Seven variables are used to calculate the PVI: i.e. coastal slope, coastal geomorphology, regional elevation, shoreline change rate, sea level change rate, mean tidal range, and significant wave height. Following a similar protocol, the Social Vulnerability Index (SVI) is calculated using four parameters such as population, land use/land cover, road network and cultural heritage (tourist locations). Although the parameters considered for SVI are not exhaustive, they are indicative of the social vulnerability status of this region. The weights for PVI and SVI are then calculated using the analytical hierarchical process (AHP) which is discussed subsequently. An overall Coastal Vulnerability Index (CVI) is further computed using the calculated indices to understand the relative vulnerability of each $2.8 \mathrm{~km}$ segment (total of 12 segments) of the shoreline. The entire procedure of vulnerability assessment (Fig. 2) involves data obtained from various sources such as remote sensing, GIS databases, and numerical modeling, which is acquired, analyzed and processed to derive each of the given parameters (Table 1). The definition of classes and assigning the scores is a necessary step for the normalization and aggregation of indicators (Torresan et al., 2012). Realizing the significance of expert judgment in deciding the scores and weights of the study, a 4-member interdisciplinary panel of experts consisting of a geologist, an oceanographer, an environmentalist and an ocean engineering specialist was set up. Integration of the expert opinions is an important step, especially in the case of data scarcity, uncertainty (source) and inconsistency (scale). In the case of Puducherry, the vulnerability classes 


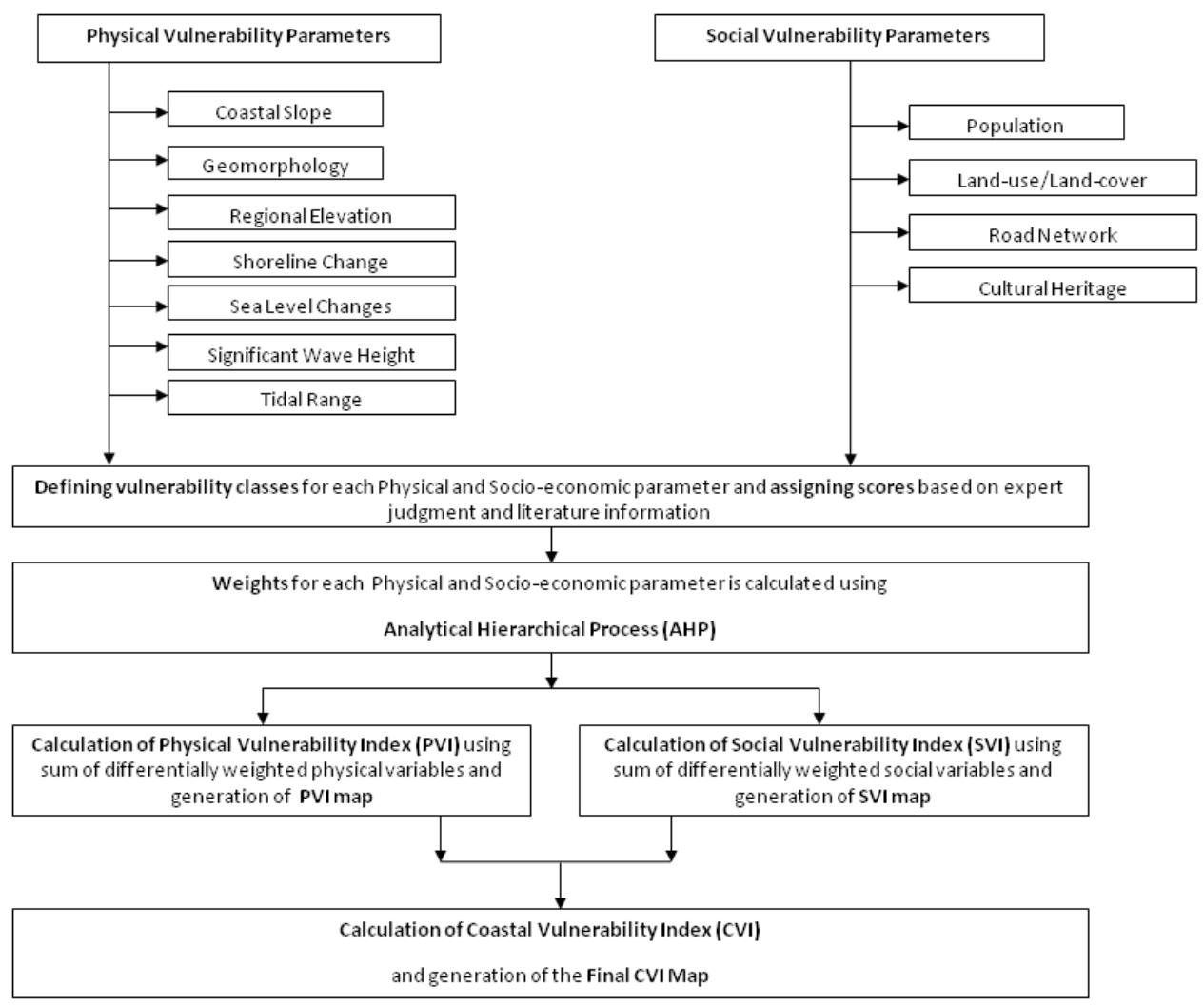

Fig. 2. Flow diagram summarizing the methodology adopted in this study for the calculation of Coastal Vulnerability Index (CVI) and generation of the CVI map.

and scores assigned are either categorical (geomorphology, land use/land cover, road network, cultural heritage) or quantitative (coastal slope, elevation, shoreline change, sea level change, significant wave height, tidal range, population) in nature. There is a considerable amount of subjectivity involved in the case of categorical classes; however, they can be used as indicators in the case of vulnerability assessment. The quantitative classes have been decided based on the expert judgments, literature information (Rao et al., 2008; Kumar et al., 2010; Kumar and Kunte, 2012) and the spectrum of values of the data set considered specific to the region. All these methodologies of classification depict site-specific relative vulnerability thresholds and thus are appropriate for regions with similar environmental conditions.

Further, a scoring method is used in order to define relative rankings within the vulnerability classes. The assignment of vulnerability scores is performed using a 1-4 scale. This is contrary to the practice of using a scale of $1-3$ or $1-5$ in the case of other vulnerability studies (Rao et al., 2008; Kumar and Kunte, 2012). The choice of this scale is purely based on the opinion of the experts. The maximum score 4 is assigned to the most important vulnerability class, while 1 represents the least important.
The significance of the parameters considered as well as their ranking criteria are discussed more elaborately in the following section.

\subsection{Physical and geological parameters (PVI)}

Seven physical-geological parameters including coastal slope, geomorphology, regional elevation, shoreline change, sea level rise, significant wave height and tidal range are considered for studying the PVI index. The entire Puducherry coast is segmented into equal lengths of $2.8 \mathrm{~km}(12 \mathrm{seg}$ ments) and assigned vulnerability rankings from 1 to 4 representing very low, low, high and very high vulnerability, respectively (Table 2 ).

\subsubsection{Coastal slope}

The coastal slope (steepness or flatness of the coastal region) is defined as the ratio of the altitude change to the horizontal distance between any two points on the coast perpendicular to the shoreline. The susceptibility of the coast due to inundation by flooding and the associated land loss is a direct function of coastal slope (Thieler and Hammer-Klose, 2000). Thus, on a steep coast, the consequence of sea level rise would be insignificant, contrary to a gently sloping coast, 
Table 1. Data used for the study.

\begin{tabular}{|c|c|c|}
\hline \multicolumn{3}{|c|}{ Physical and geological parameters } \\
\hline Parameter & Source & Period \\
\hline Coastal slope & $\begin{array}{l}\text { Modified Etopo5 obtained from data repository of National In- } \\
\text { stitute of Oceanography (Sindhu et al., 2007) }\end{array}$ & NA \\
\hline Geomorphology & LISS III (Linear Imaging Self Scanning Sensor) IRS P6 & 2011 \\
\hline Elevation & SRTM - $90 \mathrm{~m}$ resolution & NA \\
\hline Shoreline change & Landsat MSS, Landsat TM, Landsat ETM, LISS III & $\begin{array}{l}\text { 1977, 1991, 2000, 2006, 2008, } \\
2012\end{array}$ \\
\hline Sea level change & Unnikrishnan and Shankar.2007 & NA \\
\hline Significant wave height & Model output using spectral wave (SW) model of MIKE-21 & 2011 \\
\hline Tidal range & $\begin{array}{l}\text { Prediction tool and reported values in The National } \\
\text { Assessment of Shoreline Change: Puducherry Coast (2001), } \\
\text { Ramesh et al. (2011) }\end{array}$ & 2011 \\
\hline \multicolumn{3}{|c|}{ Socio-economic parameters } \\
\hline Population & Census 2001 report http://censusindia.gov.in/ & 2001 \\
\hline Land use/land cover & LISS III IRS P6 & 2012 \\
\hline Road network & GIS data & NA \\
\hline Tourist areas & GIS data & NA \\
\hline
\end{tabular}

Table 2. Vulnerability ranking criteria.

\begin{tabular}{|c|c|c|c|c|}
\hline \multirow[t]{2}{*}{ Parameter } & \multicolumn{4}{|c|}{ Coastal vulnerability ranking } \\
\hline & Very low (1) & Low (2) & High (3) & Very high (4) \\
\hline Coastal slope & $>1$ & $>0.2$ and $<1$ & $>0.1$ and $<0.2$ & $>0$ and $<0.1$ \\
\hline Geomorphology & Rocky coast & Embayed/indented coast & Dunes/estuaries and lagoons & Mudflats, mangroves, beaches, barrier-spits \\
\hline Elevation (m) & $>6$ & $>3$ and $<6$ & $>0$ and $<3$ & $<0$ \\
\hline Shoreline change $\left(\mathrm{m} \mathrm{yr}^{-1}\right)$ & Accretion $>1$ & Accretion $<1$ & Erosion $<1$ & Erosion $>1$ \\
\hline Sea level change $\left(\mathrm{mm} \mathrm{yr}^{-1}\right)$ & $<0$ & $>0$ and $<1$ & $>1$ and $<2$ & $>2$ \\
\hline Significant wave height (m) & $<0.55$ & $>0.55$ and $<1$ & $>1$ and $<1.25$ & $>1.25$ \\
\hline Tidal range $(\mathrm{m})$ & $<1$ & $>1$ and $<4$ & $>4$ and $<6$ & $>6$ \\
\hline Population (number) & $<50000$ & $>50000$ and $<100000$ & $>100000$ and $<200000$ & $>200000$ \\
\hline Land use/land cover & Barren land & Vegetated land or open spaces & Agriculture/fallow land & Urban, ecological sensitive regions \\
\hline Road network (distance from) & $2 \mathrm{~km}$ buffer & $1 \mathrm{~km}$ buffer & $500 \mathrm{~m}$ buffer & $250 \mathrm{~m}$ buffer \\
\hline Cultural heritage (tourist areas) & NA & Absent & Present & NA \\
\hline
\end{tabular}

where any rise in sea level would inundate large extents of land (Rao et al., 2008). Bathymetry shows the depth from the coast towards the open ocean and hence it can be used to estimate the near-shore slope of a region. In this study, modified ETOPO5 (ETOPO5 is a digital database of land and seafloor elevations on a $5 \mathrm{~min}$ latitude/longitude spatial grid) data has been used to generate the coastal slope. The resolution of this data set varies in resolution from a few meters \pm a few meters representing only every $150 \mathrm{~m}$ and containing very little oceanic data shallower than $200 \mathrm{~m}$. However, Sindhu et al. (2007) derived an improved shelf bathymetry for the Indian Ocean region $\left(20^{\circ} \mathrm{E}\right.$ to $112^{\circ} \mathrm{E}$ and $38^{\circ} \mathrm{S}$ to $32^{\circ} \mathrm{N}$ ) by digitizing the depth contours and sounding depths less than $200 \mathrm{~m}$ from the hydrographic charts published by the National Hydrographic Office, India. The digitized data were then gridded and used to modify the existing ETOPO5 data set for depths less than $200 \mathrm{~m}$ by combining the digitized data with the original ETOPO data set and applying blending techniques. They also validated the improvement in this data set over the original ETOPO by using a tidal circulation model and a tsunami propagation model and demonstrated the improvement in the model results. This data is obtained from the National Institute of Oceanography, India data repository and the slope for the entire study area is computed in the Arc GIS environment. The slope layer is further classified according to the ranking criteria (Fig. 3). Three classes are significant in this region, i.e. low, high and very high. A majority of the coastal stretch falls in the range of $>0.2$ and $<1$, i.e. the low vulnerability category. The stretch along Pondicherry new harbour, Muthiapet falls under very high vulnerability and areas along Manaveli, Dupuyyet, Lawspet, Kottakuppam and Kuilapalayam belong to the high vulnerability class. 


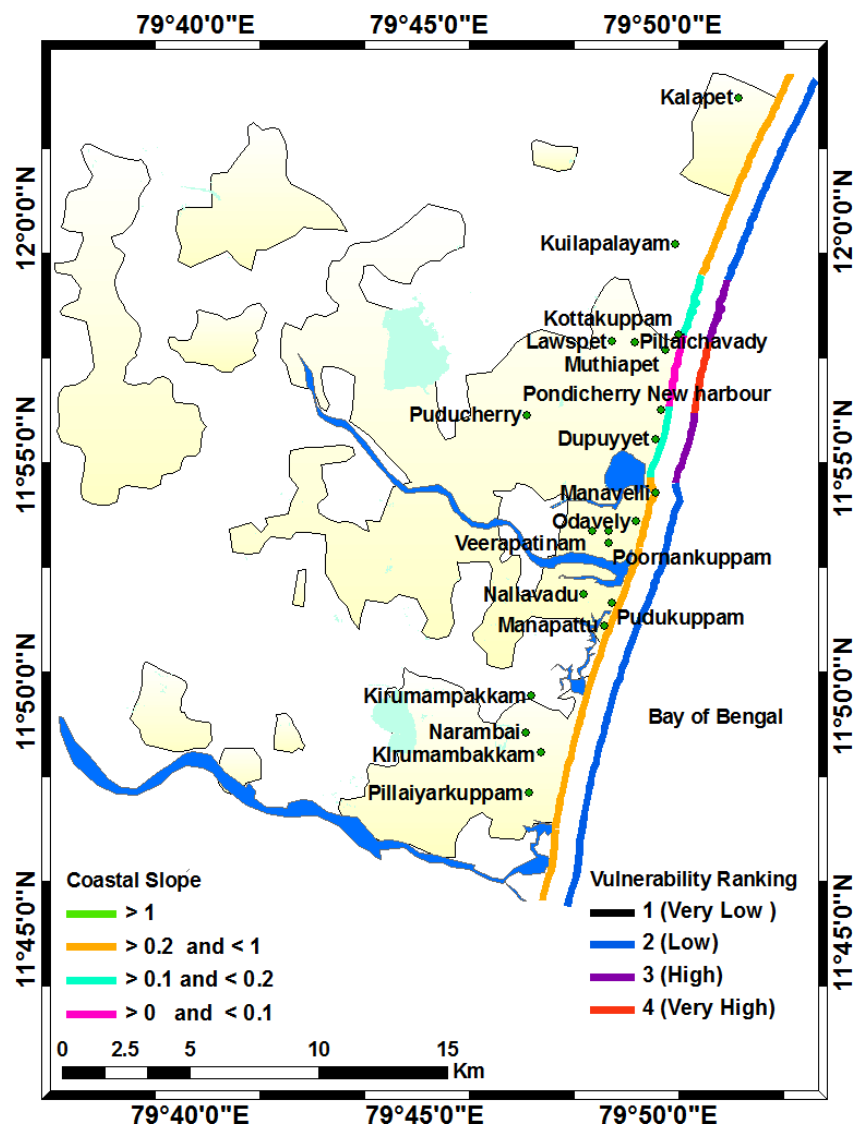

Fig. 3. Vulnerability ranking map of coastal slope.

\subsubsection{Geomorphology}

Geomorphology is defined as the study of surface landforms, processes and landscape evolution of the Earth. The morphology of the coast is shaped by tectonic and structural features, the nature of the rock forming the coast, depositional and erosive activity. It plays a pertinent role in determining the response of the coast to sea level rise, as it expresses the relative erodibility and the degree of resistance of the different landforms and the materials that compose them (Thieler and Hammer-Klose, 1999). For instance, rocky cliffs and wave-cut benches offer maximum resistance and therefore are much less vulnerable, on the other hand, the soft sandy and muddy forms such as dunes, mudflats, etc., offer the least resistance and so are extremely vulnerable to sea level rise. Thus, the study of geomorphology enables to identify the coastal areas vulnerable to hazards under present circumstances and is likely to become exceedingly susceptible as a result of global climate change.

Based on the interpretation of satellite images (Indian Remote Sensing Satellite-IRS P6 LISS III), a detailed map of the geomorphology of the region (Fig. 4) was prepared. The major landforms of the Puducherry coast are beaches, sand dunes, tidal flats and estuaries. Along the Puducherry coast,

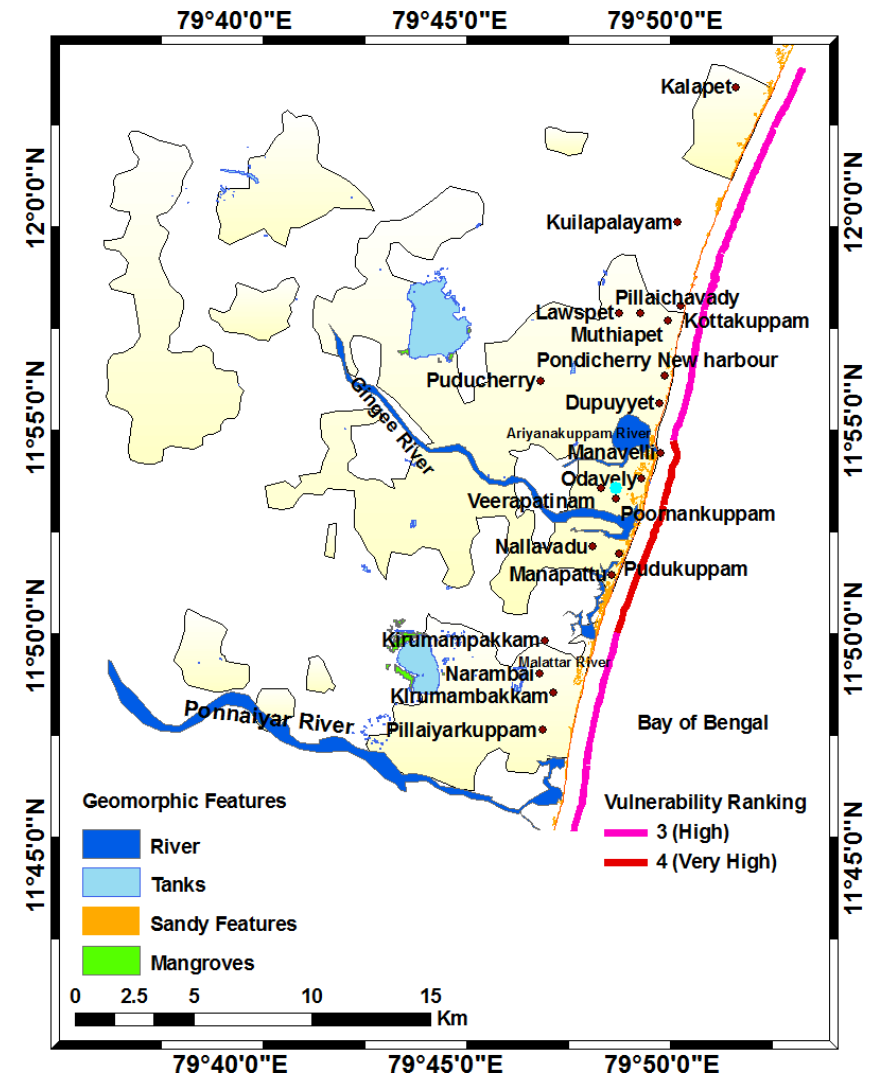

Fig. 4. Vulnerability ranking map of geomorphology.

beaches are generally narrow and severe erosion is observed along the northern segment of the coastline. In the southern segment, beaches are comparatively broader and depositional. Barrier dunes/Sand dunes are seen as continuous mounds between Ariyankuppam, Kirumambakkam, Manapattu and Narimedu areas. Estuarine mouths are prominent at Ariyanakuppam, north of Poornankuppam and in the southern segment where both Gingee and Ponnaiyar rivers join the Bay of Bengal. Throughout the landscape, tanks are distributed. Due to the presence of estuaries and beaches this region mainly comes under the high and very high vulnerability zones.

\subsubsection{Regional elevation}

Defined as the average elevation of a particular area above mean sea level, regional elevations play an important role in identifying and estimating the extent of land threatened by future climate change scenarios. Coastal regions having low elevations are considered highly vulnerable, whereas those having higher elevations are considered less susceptible. This is mainly because areas at higher elevations provide more resistance to inundation due to rising sea levels, tsunamis and storm surges. 


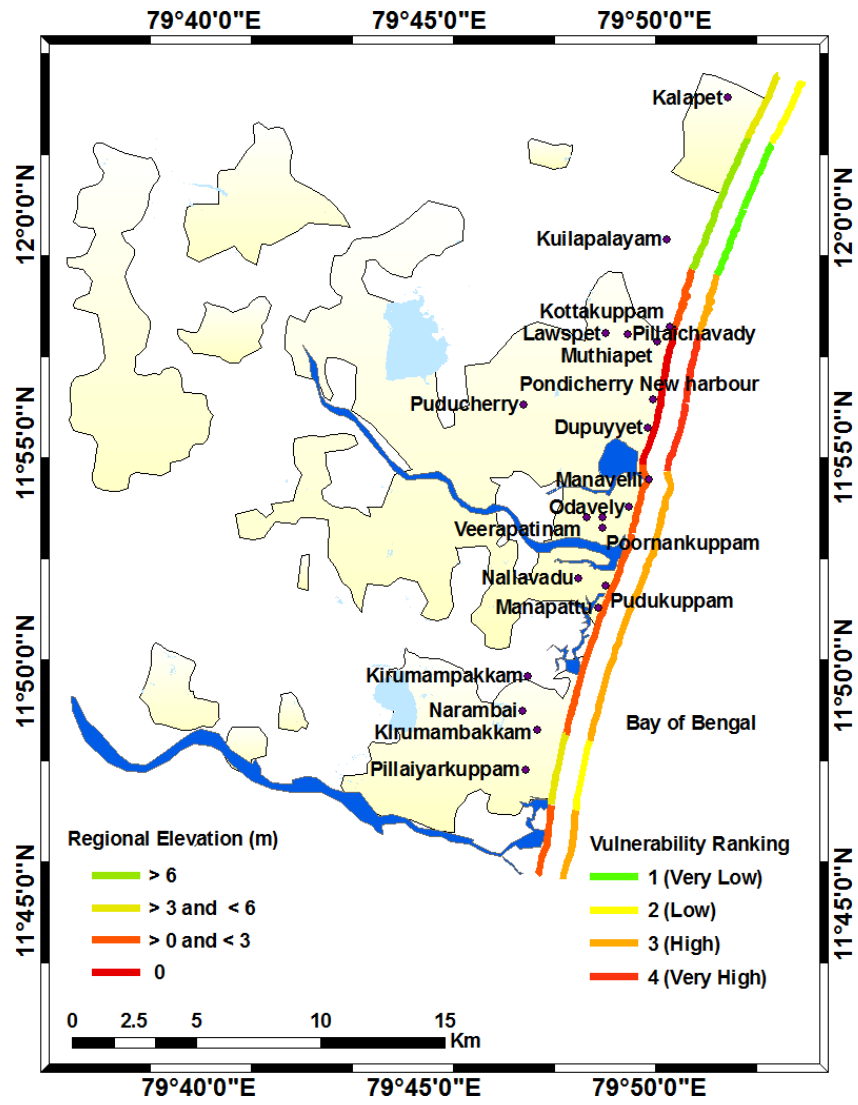

Fig. 5. Vulnerability ranking map of regional elevation.

For this study region, the coastal regional elevation is derived using the Shuttle Radar Topography Mission (SRTM) data, which is freely available from Global Land Cover Facility Site (GLCF). The mission of the Endeavour spacecraft, commonly known as SRTM (Shuttle Radar Topography Mission), ended eight years ago and since then the data has been used to generate a digital topographic map of the Earth's land surface with data points spaced every 3 arcsec (approx. $90 \mathrm{~m}$ ). The absolute horizontal accuracy of SRTM data is $20 \mathrm{~m}$ (circular error at $90 \%$ confidence) and the absolute as well as relative vertical accuracy is less than $16 \mathrm{~m}$ (linear error at $90 \%$ confidence) and $10 \mathrm{~m}$, respectively (USGS, 2006; Kellndorfer et al., 2004). Previous studies on SRTM (Zielinski and Chimel, 2007; Karwel and Ewiak, 2008; Hanson et al., 2011; Roger et al., 2013; Løvholt et al., 2012; Taubenböck et al., 2008) report that these data sets perform better than their standard specification and hence can be used for a variety of applications, such as coastal vulnerability or inundation mapping. In our analysis, the aim of using DEM is to evaluate and separate the lowest area from other higher areas along the coasts for which the SRTM data proves sufficient with its specifications.

The stretch of Puducherry coast covers all the four vulnerability classes of regional elevation (Fig. 5). However, the majority of the coast comes under the high and very high vulnerability zones. The coastline along Muthiapet and Dupuyyet has a very high vulnerability factor and areas of Manavelli and Narambai constitutes a high vulnerability zone. The region between Kalapet and Kuilapalayam lies in a very low to low vulnerability zone.

\subsubsection{Shoreline change}

Shoreline is the interface between land and water. Healthy beaches and shorelines are essential to the quality of life along the coast, and also provide buffers for storms and critical habitats for many species of plants and animals. Shoreline changes are a result of coastal processes, which are mainly controlled by wave characteristics, near-shore circulation, sediment characteristics and beach forms. The breaking waves and currents in the near-shore zone are responsible for the transport of shoreline sediments resulting in shoreline change. This scenario is part of a process called littoral transport, which moves the eroded material in the coastal zone by means of waves and currents. In the context of coastal vulnerability, accreting coastlines are considered less vulnerable, as they result in the addition of land areas by moving towards the ocean. On the other hand, eroding coastlines are considered highly vulnerable because of the resultant loss of natural as well as man-made resources associated with it. LANDSAT MSS, TM, ETM and IRS-LISS III images covering the Puducherry coastline for the years 1977, 1991, 2000, 2006, 2008 and 2012 are used for processing in ERDAS software. The extracted shorelines are then vectorized to calculate the shoreline change using the DSAS tool of Arc-GIS (USGS, 2005). The onshore transects are laid at an interval of every $250 \mathrm{~m}$ along the coastline. The DSAS tool calculates several statistics which are useful in understanding the shoreline trends from a temporal perspective. Considering the rate of change, vulnerability ranking is assigned to the 12 coastal segments.

The shoreline change map is constructed based on the Net shoreline movement (NSM) and end point rate (EPR) criteria; the zones having positive NSM and EPR are mainly the accreting zones and those depicting negative values are eroding zones (Fig. 6). The northern part of the coastline is mainly erosive and the southern part has accreting trends. The shoreline along Kalapet is an eroding stretch and, based on the above-mentioned ranking criteria, belongs to high vulnerability class. The regions between Gingee and Ariyanakupum river is an accreting coastline and hence has a very low vulnerability. The port plays an important element as north of the port is erosive and south of the port is showing accretion. Consequently, the shoreline along Duppuyet is highly vulnerable.

\subsubsection{Sea level changes}

Sea level change is one of the most important consequences of climate change. Mean sea level is usually described as a 


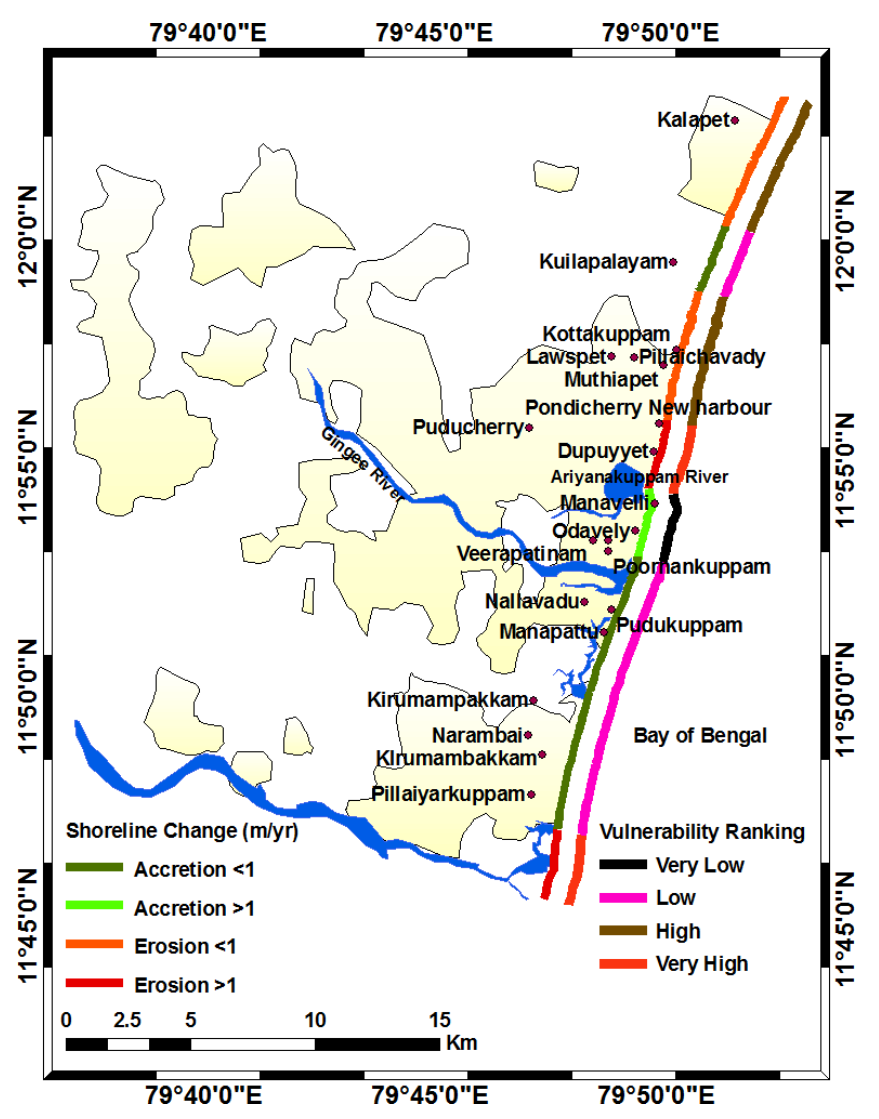

Fig. 6. Vulnerability ranking map of shoreline change rate.

tidal datum that is the arithmetic mean of hourly water elevations observed over a specific $19 \mathrm{yr}$ cycle. "Global sea level rise" refers to the increase currently observed in the average global sea level trend, which is primarily attributed to changes in ocean volume due to two factors: ice melt and thermal expansion. Increase in global atmospheric temperature causes a rise in ocean temperature and subsequent melting of glaciers, leading to rise in global sea level. Global sea level rise studies have been carried out extensively in the last two decades due to the availability of monthly mean sea level data through the permanent service for mean sea level (Woodworth and Player, 2003). A sea level rise of approximately $2.3 \mathrm{~m}^{\circ} \mathrm{C}^{-1}$ is expected within the next $2000 \mathrm{yr}$ (Levermann et al., 2013). Unnikrishnan and Shankar (2007) estimated the trends in sea level rise for the North Indian Ocean coasts by using the tide gauge data available at the PMSL site and correcting their global isostatic adjustment (GIA). In their study, they have considered all tide gauge records of the Arabian Sea and the Bay of Bengal that have a duration of at least $20 \mathrm{yr}$. Eventually they estimated trends at stations that have records longer than $40 \mathrm{yr}$, and applied corrections for vertical land movements owing to Glacial isostatic adjustments using the ICE-5G model (Peltier, 2001, 2004). Their results estimated a regional average of $1.29 \mathrm{~mm} \mathrm{yr}^{-1}$.
Mahendra et al. (2011) calculated the sea level changes using the tide gauge data of Chennai for a period of $54 \mathrm{yr}$ and estimated a value of $0.085 \mathrm{~mm} \mathrm{yr}^{-1}$. In this study the average of $1.29 \mathrm{~mm} \mathrm{yr}^{-1}$ is used. The rationale behind using this value is that this estimate is consistent with the global estimate reported in the Third assessment report of IPCC (Unnikrishnan and Shankar, 2007). In their paper Kumar and Kunte (2012) assigned this value as a medium vulnerability class for their study area of Chennai. As the scoring in our case varies between $1-4$, we have classified it as a high vulnerability class with a ranking of 3 .

\subsubsection{Significant wave height}

Significant wave height (SWH) is used as an alternative to wave energy and is important in studying the vulnerability of shorelines. It is the average height (trough to crest) of onethird of the waves in a wave spectrum for a given period of time.

Wave energy is directly related to the square of wave height by the following formula:

$E=1 / 8 \rho g H^{2}$,

where $E$ is energy density, $H$ is wave height, $\rho$ is water density and $g$ is acceleration due to gravity. Increase in wave height causes an increase in wave energy, which subsequently results in increased erosion and inundation along the shore, causing loss of land. Hence, coastlines experiencing high wave heights are considered more vulnerable than those which are exposed to low wave heights.

For the Puducherry region, a spectral wave (SW) model of MIKE-21 is used to compute the significant wave height for the year 2011. By solving the spectral wave action balance equation, this model simulates the growth, decay and transformation of the wind-generated waves and swells in the offshore and coastal regions (Vethamony et al., 2006). Six-hourly SWH are generated by forcing the model with NCEP/NCAR Reanalysis wind data of $2.5 \times 2.5^{\circ}$ resolution available from the site http://www.esrl.noaa.gov. The model is also validated with DS05 buoy data from 2005 and a correlation of 0.87 is obtained with a bias of -0.08 . The average values are calculated and considered for assigning vulnerability rating. The significant wave height at Puducherry rarely exceeds an average of $0.9 \mathrm{~m}$. At Puducherry coast, deepwater waves occur from south and southwest during southwest monsoon and from northeast during northeast monsoon. Puducherry coast falls in the low vulnerability class from the point of significant wave height.

\subsubsection{Tidal range}

Tidal range is defined as the vertical difference (in meters) between the high tide and the consecutive low tide. Tides are the rise and fall of sea levels caused by the combined effects of the gravitational forces exerted by the moon and the sun 
and the rotation of the Earth. Both permanent and episodic inundation hazards are linked to tidal range. Gornitz (1991) suggests that high tidal range is associated with stronger tidal currents, which have the capacity to cause erosion and transport of sediment. He specifies further that macro-tidal coasts $(>4 \mathrm{~m}$ ) will be more vulnerable than those with lesser ranges. Thus, a coastal area is considered highly vulnerable if it experiences high tidal range, whereas those with low tidal ranges are designated to be of low vulnerability.

In the current study, WXtide software has been used to predict tide data along the Cuddalore coast for the year 2011. The tidal range for a smaller region generally does not fluctuate much in a year. The average tide range of this region is between $0.7-0.8 \mathrm{~m}$. The National Assessment of Shoreline Change: Puducherry Coast (2011) reports that tidal range for Puducherry coast is low and the maximum range during a spring tide is around $0.8 \mathrm{~m}$.

Recorded tide levels at Puducherry with respect to chart datum are:

- Mean high water spring (MHWS): $+1.30 \mathrm{~m}$

- Mean high water neap (MHWN): $+1.00 \mathrm{~m}$

- Mean low water neap (MLWN): $+0.70 \mathrm{~m}$

- Mean low water spring (MLWS): $+0.49 \mathrm{~m}$.

(The National Assessment of Shoreline Change: Puducherry Coast, 2011; Ramesh et al., 2011)

Hence in view of both the data obtained from the prediction tool and the literature, the entire coastline is classified into the very low vulnerability class.

\subsection{Socio-economic parameters}

\subsubsection{Population}

The population data is essential in order to understand the effect and the dimension of the natural disaster. Human beings' vulnerability is considered a social condition, or a measure of the resilience of society to a disaster. By using census data and the mapping capabilities of a GIS, our goal is to put in place a blueprint with which we can quickly identify areas where populations are disproportionately susceptible to disaster impacts. In the current study, the census data of 2001 is considered for the region to find zones with a higher population distribution in comparison to others. A population map is prepared in the Arc-GIS environment where the individual polygons represent the important towns of Puducherry. The minimum population of a town is 54430 (Bahour) and the maximum is observed in the Pondicherry town, i.e. 220865. Ozukarai also has a large population that resides along the coastal belt. Based on the ranking criteria, three vulnerability classes of low, high and very high are obtained for this region (Fig. 7).

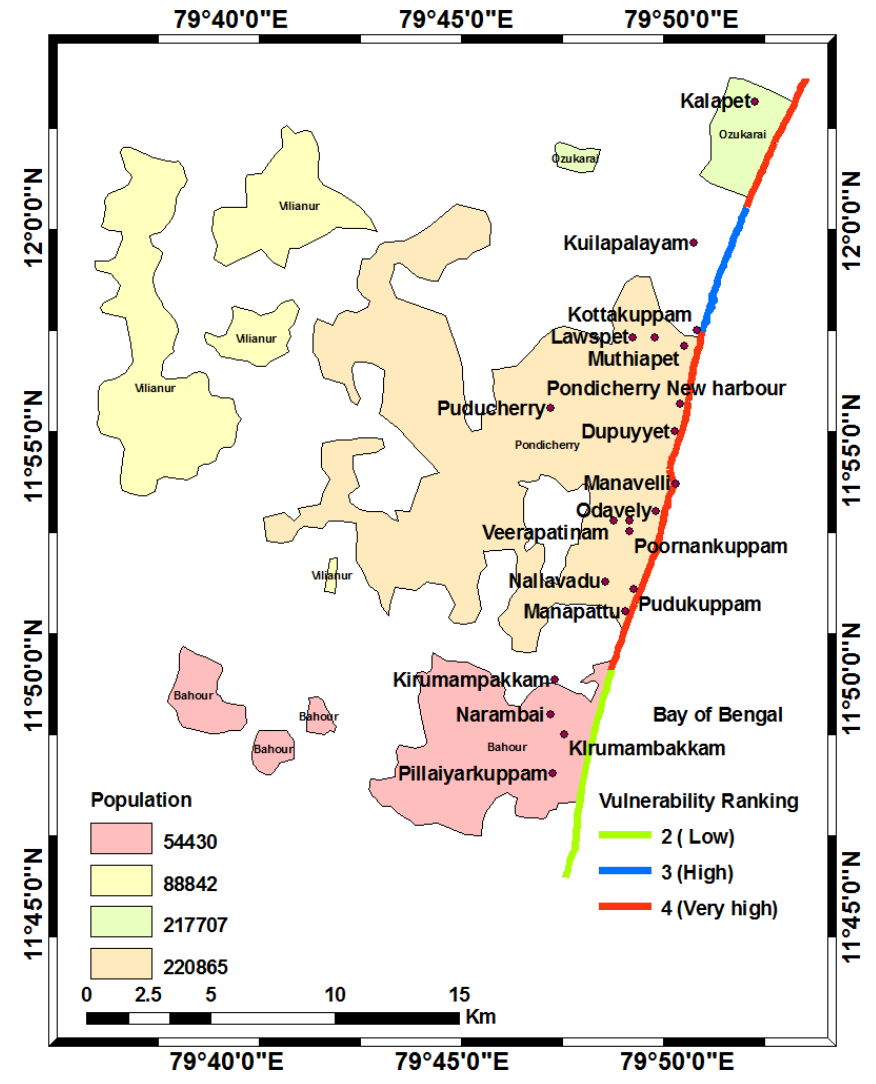

Fig. 7. Vulnerability ranking map of population.

\subsubsection{Land use/land cover}

A land use/land cover map is essential to understanding the land use/land cover classes in a particular region and its help in increasing or diminishing the vulnerability of an area. LU/LC of a region are attributed to the anthropogenic activities (Mani Murali et al., 2006) in addition to the climate changes. For instance, an urban area along the shoreline such as in the case of Puducherry makes the region more vulnerable to natural calamity. In the current study, a LU/LC map is generated using supervised classification techniques in ERDAS Imagine software on a $23.5 \mathrm{~m}$ resolution LISS III image of 2012 by applying the maximum likelihood algorithm. From the land use/land cover map (Fig. 8, Table 3) it can be seen that the agricultural area and fallow land (49\% of the total land area), comprising mainly cropland and plantation, dominate this region. The forest land is almost nil in Puducherry and most of the vegetation (approx. $3 \%$ of the total land) comprises those which are along the settlements. Only $0.4 \%$ of the total area comprises the sandy beaches. The urban area covers about $9.8 \%$ of total land use/land cover. The main areas of urban agglomeration are Puducherry and Kalapet and hence have a very high to high vulnerability. Other areas have been ranked as low vulnerability as they have less urban build-up and are not entirely barren. 


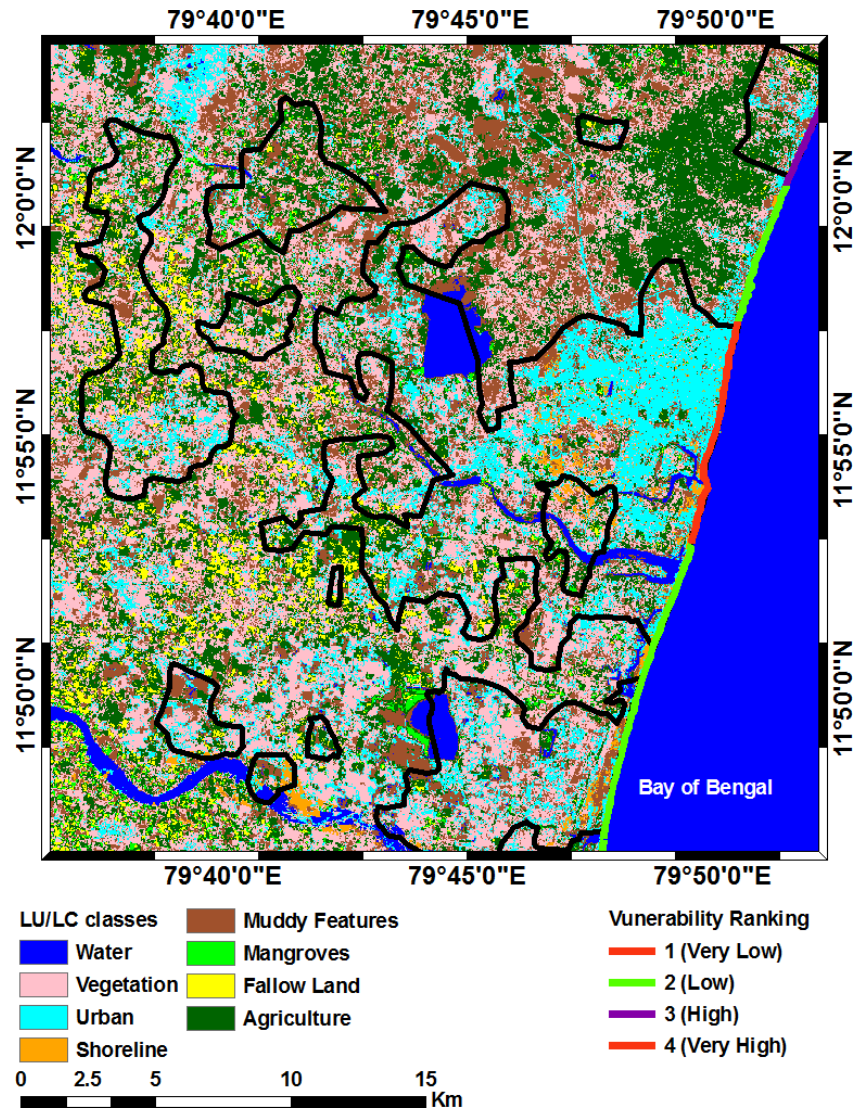

Fig. 8. Vulnerability ranking map of land use/land cover.

Table 3. Areal distribution of LU/LC classes as percentage cover.

\begin{tabular}{lr}
\hline Class name & \% Cover \\
\hline Water & 22 \\
Barren/muddy areas & 14 \\
Sandy beach & 0.4 \\
Agriculture & 21.2 \\
Fallow & 29.4 \\
Vegetation & 3.2 \\
Urban & 9.8 \\
\hline Total & 100 \\
\hline
\end{tabular}

\subsubsection{Road networks}

Road networks are essential during a natural calamity, especially with reference to providing relief work. A disruption in road networks due to a natural calamity can lead to a cutoff and increase the impact of the calamity manifold due to scarcity of resources. The road network data was created in the GIS environment using a combination of available LISS III data and rectified Google maps. The classification of the road network has been done subjectively by making buffers of $250 \mathrm{~m}, 500 \mathrm{~m}, 1 \mathrm{~km}, 2 \mathrm{~km}$ or beyond from the shoreline. It is considered that the proximity of a particular section of

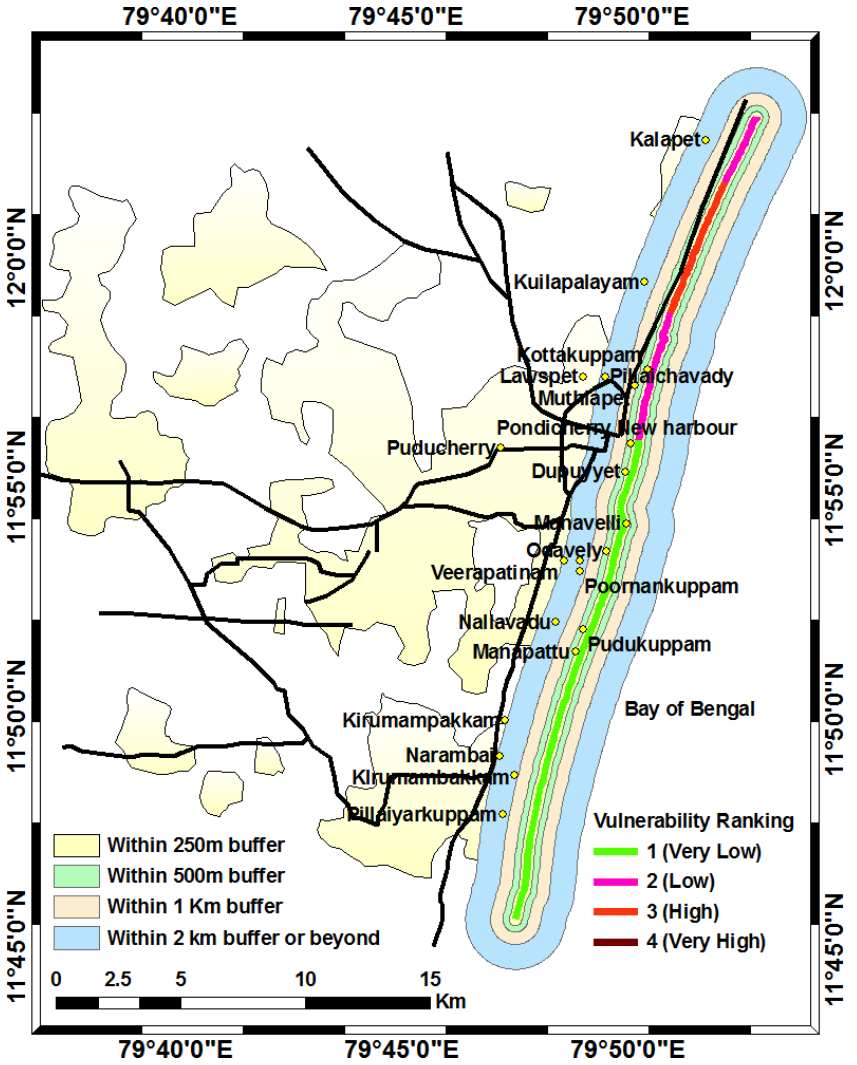

Fig. 9. Vulnerability ranking map of road network.

the road to the shoreline makes it more vulnerable. Based on this criterion, a short stretch of road from Kalapet to Kuilapalayam appears to be vulnerable and is classified under the high vulnerability zone. A majority of the road segments are $2 \mathrm{~km}$ or beyond and hence are classified under very low vulnerability category (Fig. 9).

\subsubsection{Cultural heritage (tourist areas)}

The distribution of tourist areas is considered as it has a pertinent socio-economic implication as the cultural heritage of a region. Damage caused due to a disaster on a monument or tomb can lead to economic loss, and moreover more people are considered to gather at these places, which can cause substantial human loss in the case of a natural disaster. Considering Puducherry to be essentially a tourist destination, this parameter has been considered by plotting the location of important places in GIS. Two classes are prepared based on the criteria: whether a tourist area is present or absent near the shoreline (Fig. 10). In order to ensure consistency, the ranking is given as 2 if a tourist area is absent or 3 if it is present. Most of the tourist areas are located in Puducherry town and hence the extent along it is considered to be highly vulnerable. Although the area along Kalapet is not a tourist destination, it has been ranked as highly vulnerable, as the university is located here. 


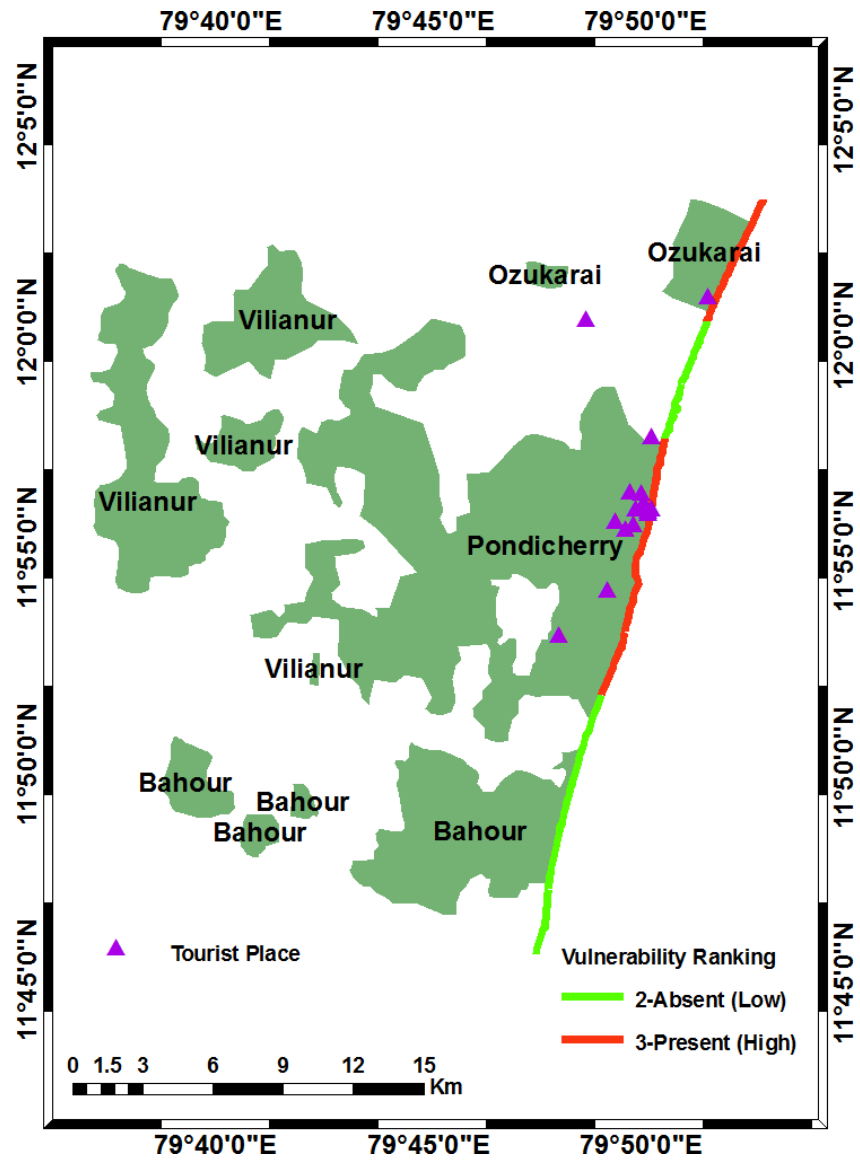

Fig. 10. Vulnerability ranking map of distribution of tourist areas.

\subsection{Analytical hierarchical process and calculation of vulnerability index}

Analytical hierarchical process (AHP) was developed by Saaty (1977) to calculate the needed weighting factors with the help of a preference matrix, where all identified relevant criteria are compared against each other with reproducible preference factors. AHP selects the best alternatives by considering both the objective and subjective factors. In this analysis, a general protocol is followed for calculating the weights for both PVI and SVI. In the first step, pair-wise comparisons are carried out for all factors to be considered, and the matrix is completed by using scores based on their relative importance. In the construction of a pair-wise comparison matrix, each factor is rated against every other factor by assigning a relative dominant value between 1 and 9 to the cell concerned. The significance of the dominant scale values is given in Table 4. Having a comparison matrix (Tables 5 and 7), a priority vector is computed which is the normalized Eigen vector of the matrix. This is done by dividing each of the columns by the corresponding sum (Tables 6 and 8). As the last step, the average values of each row are computed and these are used as weights in the objective hierarchy for
Table 4. Scale of comparison.

\begin{tabular}{ll}
\hline Intensity of importance & Description \\
\hline 1 & Equal importance \\
3 & Moderate importance \\
5 & Strong importance \\
7 & Very strong importance \\
9 & Extreme importance \\
$2,4,6,8$ & Intermediate values \\
Reciprocals & Values for inverse comparison \\
\hline
\end{tabular}

calculating the PVI and SVI. AHP allows both sub-criteria as well as main criteria comparison, however, for the present study the latter has been used and the weights have been reported.

CVI in most of the vulnerability studies is expressed as the square root of the product of the ranking factors divided by the number of parameters considered. According to Gornitz (1991), although CVI can be expressed as a sum of the parameters, the CVI computed as the product of parameters has the advantage of expanding the range of values. On the contrary, Diez et al. (2007), suggest that the CVI as the sum of differentially weighted variables represent the environmental variability more appropriately. In the present study, PVI and SVI have been calculated by using both methods and it is found that the method of summation suitably expresses the conditions in this region.

The approach used here to derive weights is different from the methodologies used previously in the vulnerability studies conducted in India. For instance, Rao et al. (2008) obtained the differential weights for the parameters by multiplying the vulnerability rank values by arbitrary multiplication factors based on the relative significance of the five variables considered. They have ranked geomorphology and slope as more important parameters in comparison to others (shoreline change, SWH, Tidal range) and hence have given them the highest weight of 4 and have subsequently given 2 to shoreline change and no weights to tidal range and SWH. Ju et al. (2012) performed a GIS-based suitability assessment for Laoshan district wherein they have used AHP as a method to derive weights. Similarly in this study, weights for the various parameters have been derived using analytical hierarchical process. This is because, although in relative terms, a particular parameter may have more significance than the other, giving absolute weights based on the discretion of the investigators highly undermines the individual contribution of each variable. For instance, coastal slope and geomorphology are often considered significant factors in the case of vulnerability to sea level rise; however, assigning them the same value does not define their comparative contribution. Moreover, arbitrary values can be considered in the case of vulnerability assessment for a particular type of calamity, however for an overall assessment they can be 
Table 5. Comparison matrix of physical-geological variables.

\begin{tabular}{lrrrrrrr}
\hline & $\begin{array}{r}\text { Tidal } \\
\text { range }\end{array}$ & $\begin{array}{r}\text { Significant } \\
\text { wave height }\end{array}$ & $\begin{array}{r}\text { Sea } \\
\text { level }\end{array}$ & $\begin{array}{r}\text { Shoreline } \\
\text { change }\end{array}$ & Elevation & Geomorphology & Slope \\
\hline Tidal range & 1.00 & 0.50 & 0.33 & 0.20 & 0.14 & 0.11 & 0.11 \\
Significant wave height & 2.00 & 1.00 & 0.33 & 0.25 & 0.20 & 0.13 & 0.11 \\
Sea level & 3.00 & 3.00 & 1.00 & 0.33 & 0.25 & 0.17 & 0.14 \\
Shoreline change & 5.00 & 4.00 & 3.00 & 1.00 & 0.33 & 0.20 & 0.17 \\
Elevation & 7.00 & 5.00 & 4.00 & 3.00 & 1.00 & 0.33 & 0.25 \\
Geomorphology & 9.00 & 8.00 & 6.00 & 5.00 & 3.00 & 1.00 & 0.33 \\
Slope & 9.00 & 9.00 & 7.00 & 6.00 & 4.00 & 2.00 & 1.00 \\
& 36.00 & 30.50 & 21.67 & 15.78 & 8.93 & 3.94 & 2.12 \\
\hline
\end{tabular}

Table 6. Normalized matrix of physical-geological variables.

\begin{tabular}{lrrrrrrrrrr}
\hline & $\begin{array}{r}\text { Tidal } \\
\text { range }\end{array}$ & $\begin{array}{r}\text { Significant } \\
\text { wave height }\end{array}$ & $\begin{array}{r}\text { Sea } \\
\text { level }\end{array}$ & $\begin{array}{r}\text { Shoreline } \\
\text { change }\end{array}$ & Elevation & Geomorphology & Slope & Sum & Mean & 100.00 \\
\hline Tidal range & 0.03 & 0.02 & 0.02 & 0.01 & 0.02 & 0.03 & 0.05 & 0.17 & 0.02 & 2.41 \\
Significant wave height & 0.06 & 0.03 & 0.02 & 0.02 & 0.02 & 0.03 & 0.05 & 0.23 & 0.03 & 3.23 \\
Sea level & 0.08 & 0.10 & 0.05 & 0.02 & 0.03 & 0.04 & 0.07 & 0.39 & 0.06 & 5.53 \\
Shoreline change & 0.14 & 0.13 & 0.14 & 0.06 & 0.04 & 0.05 & 0.08 & 0.64 & 0.09 & 9.13 \\
Elevation & 0.19 & 0.16 & 0.18 & 0.19 & 0.11 & 0.08 & 0.12 & 1.05 & 0.15 & 14.97 \\
Geomorphology & 0.25 & 0.26 & 0.28 & 0.32 & 0.34 & 0.25 & 0.16 & 1.85 & 0.26 & 26.48 \\
Slope & 0.25 & 0.30 & 0.32 & 0.38 & 0.45 & 0.51 & 0.47 & 2.68 & 0.38 & 38.25 \\
\hline
\end{tabular}

misleading. Clearly, AHP proves to be more advantageous in the case of a multi-index integrated evaluation.

In order to indicate the likelihood that the matrix judgments were generated randomly, an index of consistency known as a consistency ratio (CR) is used in the process of synthesis of the AHP (Saaty, 1977).

$\mathrm{CR}=\mathrm{CI} / \mathrm{RI}$.

Here, the consistency index (CI) can be expressed as

$\mathrm{CI}=(\lambda \max -n) /(n-1)$,

where $\lambda$ max is the largest or principal Eigen value of the matrix, and $n$ is the order of the matrix. The random index (RI) is defined as the average of the resulting consistency index that depends on the order of the matrix (Table 9) given by Saaty (1977). Generally, a consistency ratio (CR) of a value of 0.10 or less is considered relevant (Saaty, 1977).

Since the consistency ratio for both the variables (Table 10) is less than 0.1 they can be considered for further calculation.

The weights derived using AHP are used for calculating the PVI and SVI, where

$$
\begin{aligned}
\mathrm{PVI} & =W_{1} X_{1}+W_{2} X_{2}+W_{3} X_{3}+W_{4} X_{4}+W_{5} X_{5} \\
& +W_{6} X_{6}+W_{7} X_{7} .
\end{aligned}
$$

Equation (4) represents the physical vulnerability index (physical parameters), where $W_{n}$ is the weight value of each variable, and $\mathrm{Xn}$ is the vulnerability score of each variable.

$\mathrm{SVI}=W_{1} X_{1}+W_{2} X_{2}+W_{3} X_{3+} W_{4} X_{4}$

Equation (5) represents the socio-economic vulnerability index (Socio-economic parameters), where $W_{n}$ is the weight value of each variable, and $\mathrm{Xn}$ is the vulnerability score of each variable.

$\mathrm{CVI}=(\mathrm{PVI}+\mathrm{SVI}) / 2$

We have used the above formula (6) considering that both physical and socio-economic factors have equal contribution in coastal vulnerability.

The values of each variable for each coastal segment are obtained by multiplying the vulnerability rank values by the corresponding weight factors of the respective variables. These are further processed in the geographic information system (GIS) environment (ArcGIS). The entire coast is considered a linear feature in which every $2.8 \mathrm{~km}$ segment along the coast is analyzed for its vulnerability. The PVI, SVI and CVI values for the different segments of the coastline are further classified into low (lesser than 25th percentile), medium (between 25th and 50th percentile) and high vulnerable (greater than 50th percentile) classes. 
Table 7. Comparison matrix of socio-economic variables.

\begin{tabular}{lrrrr}
\hline & Cultural heritage & Road networks & LU-LC & Population \\
\hline Cultural heritage & 1.00 & 0.33 & 0.20 & 0.11 \\
Road networks & 2.00 & 1.00 & 0.25 & 0.11 \\
LU-LC & 5.00 & 4.00 & 1.00 & 0.20 \\
Population & 9.00 & 9.00 & 5.00 & 1.00 \\
& 17.00 & 14.33 & 6.45 & 1.42 \\
\hline
\end{tabular}

Table 8. Normalized matrix of socio-economic variables.

\begin{tabular}{lrrrrrrr}
\hline & Cultural heritage & Road networks & LU-LC & Population & Sum & Mean & 100.00 \\
\hline Cultural heritage & 0.06 & 0.02 & 0.03 & 0.08 & 0.19 & 0.05 & 4.78 \\
Road networks & 0.12 & 0.07 & 0.04 & 0.08 & 0.30 & 0.08 & 7.61 \\
LU-LC & 0.29 & 0.28 & 0.16 & 0.14 & 0.87 & 0.22 & 21.72 \\
Population & 0.53 & 0.63 & 0.78 & 0.70 & 2.64 & 0.66 & 65.89 \\
\hline
\end{tabular}

Table 9. Showing values of RI (Saaty and Vargas 1991), with $n=$ order of the matrix.

\begin{tabular}{rrrrrrrr}
\hline$N$ & 2 & 3 & 4 & 5 & 6 & 7 & 8 \\
\hline RI & 0.00 & 0.52 & 0.90 & 1.12 & 1.24 & 1.32 & 1.41 \\
\hline
\end{tabular}

\section{Results and discussions}

\subsection{Physical vulnerability index}

The PVI presented in this study has been calculated by using seven variables of coastal slope, geomorphology, regional elevation, shoreline changes, sea level rise, significant wave height and tidal ranges. The slope, geomorphology, regional elevation and erosion rate variables are important parameters for physical vulnerability as they vary along the coastline. However, the remaining variables, including sea level change, significant wave height and mean tide range do not vary with respect to vulnerability. This is because the extent of the shoreline under consideration is small and so only one relevant value is obtained for the data. Rao et al. (2008) considered slope as a relatively more appropriate variable, as slope represents the area whereas elevation denotes a point. However, Kumar et al. (2010) suggest that addition of regional elevation is equally essential. In this study, coastal slope has been given the maximum priority while assigning weight, as it plays a major role in the case of disasters like tsunamis, storm surges and flooding. Coastal elevation that represents the vertical level of the terrain has also been included as an additional parameter. An analysis of the synthesis of the PVI maps also shows that geomorphology is a governing factor of vulnerability after coastal slope. Dinesh Kumar (2006) studied the implication of sea level rise on the coastal zone of Cochin and revealed that the mean beach slope and relief play a vital role in land loss of the region. Most of the Puducherry coast is covered with estuaries, sand dunes and beaches classifying it into a priority zone. According to Rao et al. (2008), the rate of shoreline change is only a general indicator of the behavior of the coast and hence cannot be used to predict the subsequent trend of the coastline with time. However in our present study we consider it the fourth most important parameter, as it contributes to a significant variance to the calculated PVI. The national assessment of shoreline change - Puducherry coast (2011) report specifies the role of fetch, and therefore the resultant wave energy in the erosion rates observed in the Puducherry coast. They also mention that emplacement of shoreline protection structures such as seawalls/riprap and revetments can result in both active and passive erosion of the beach. Some of the highest erosion zones are found along the northern side of the Puducherry Port, mainly because hard structures often play a defining role in the case of shoreline trends.

Figure 11 shows the vulnerability map prepared based on the physical vulnerability index. The PVI values range from 215 to 345 . It can be observed that the region along Kottakupam, Muthiapet and Pondicherry new harbor, Dupuyyet as well as the region between Poornankuppam and Pudukuppam is highly vulnerable. Based on the PVI calculation, almost $50 \%$ of the shoreline comes under the high vulnerability zone, whereas $25 \%$ of the coastline has medium and $25 \%$ has low vulnerability.

\subsection{Social vulnerability index}

Most of the previously developed coastal vulnerability/sensitivity indices acknowledge that the addition of socioeconomic variables would assist in defining vulnerable areas (McLaughlin et al., 2002). This proves to be difficult as several problems are encountered in assessing socio-economic vulnerability indicators due to inherent drawbacks involved in ranking socio-economic data on an interval scale. Hence 


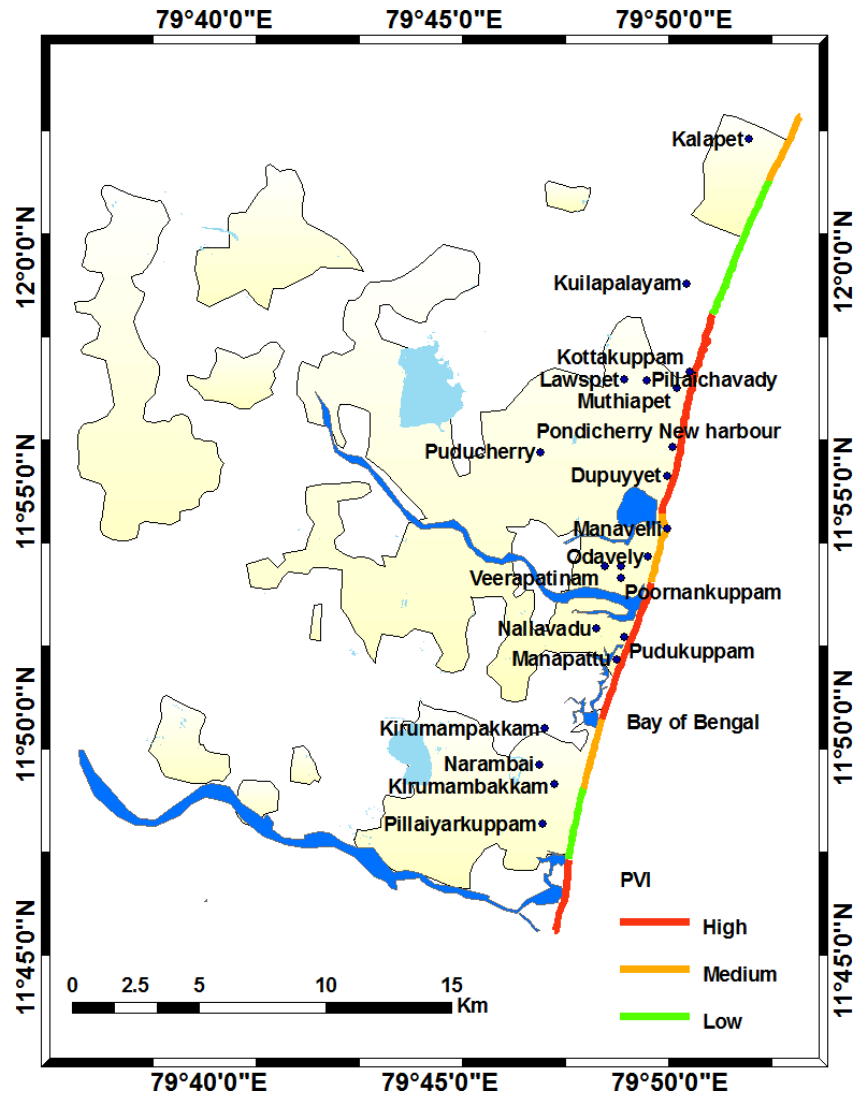

Fig. 11. Physical vulnerability index map.

they are generally excluded from coastal vulnerability index (CVI) calculations. However, socio-economic variables are significant factors contributing to coastal vulnerability mainly because socio-economic changes occur more often and more rapidly than physical process changes (Szlafsztein, 2005). It is hence imperative to consider socio-economic data along with physical variables as this would enhance the accuracy and clarity of results related to coastal vulnerability, as the magnitude of a natural calamity is often described in terms of the devastation its causes to human, natural and anthropogenic resources.

Here, population, land use/land cover, road network and location of tourist areas are considered to calculate the social vulnerability index (SVI). The region along Kalapet, Kottakuppam and Ariyanakuppam has high vulnerability and that along Kirumambakkam and Kuilapalayam has a low vulnerability (Fig. 12).

All these factors can be used as indicators that can help in making a qualitative analysis of the vulnerability situation along the Puducherry coast.

\subsection{Coastal vulnerability index}

The sensitivity of a coastal region to coastal hazards can be effectively assessed by using the CVI. For the coast

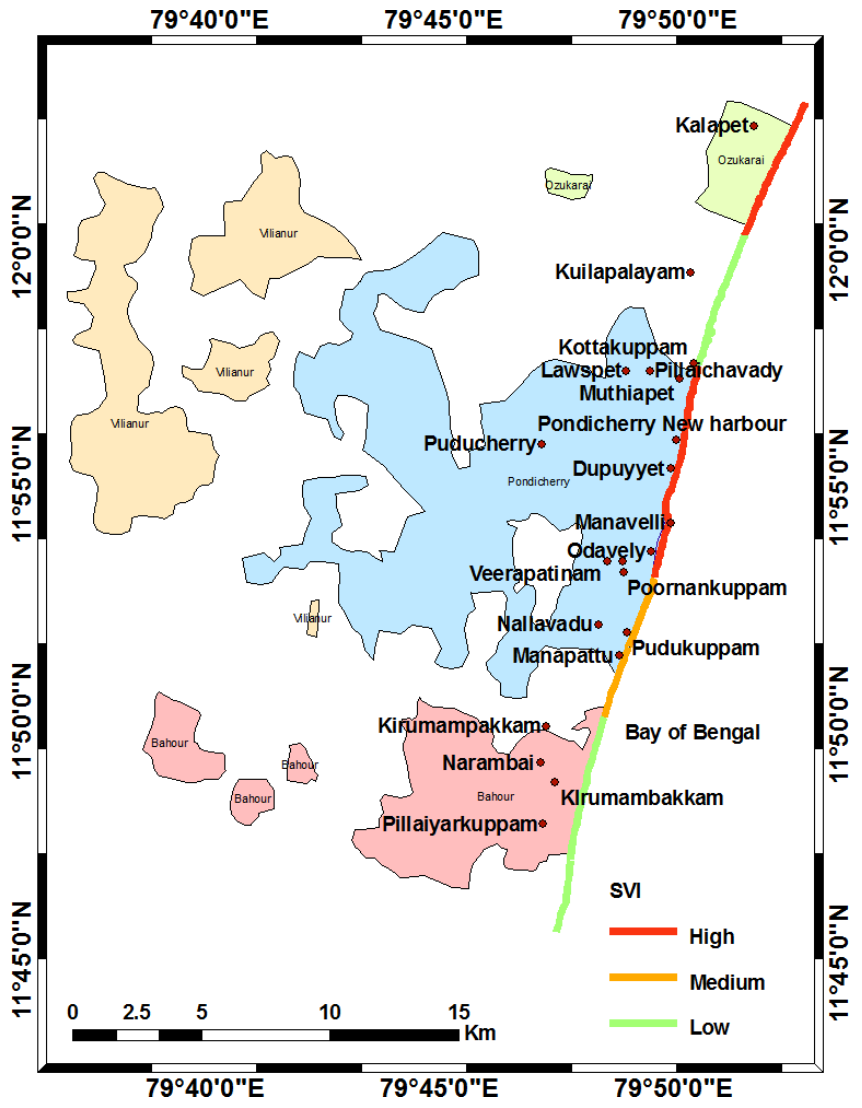

Fig. 12. Socio-economic vulnerability index map.

of Puducherry, both physical-geological as well as socioeconomic parameters have been considered for the calculation of CVI by giving them equal weight. This is because although the former regulates the intensity and enormity of the disaster, the latter characterizes it consequence and impact.

The CVI calculated through this approach ranges from 211 to 362 . The extent to which the contributing variables differ is an important criteria based on that the CVI index varies (Abuodha and Woodroffe, 2006). Accordingly, the coastal vulnerability map (Fig. 13) for the Puducherry coast is generated by grouping various coastal segments into the 3 vulnerability classes. Depending on this classification, the entire coastal extent between Muthiapet and Pudukuppam as well as the northern part of Kalapet is designated the high vulnerability zone, which constitutes $50 \%$ of the coastline. The region between the southern coastal extent of Kalapet and Lawspet is the medium vulnerability zone and the remaining $25 \%$ of the shoreline is the low vulnerability zone. The maps obtained from this study represent the vulnerable areas based on the 11 parameters considered (physical-geological, socio-economic factors). They highlight the more challenging regions along the Puducherry coast that demand further attention and hence need to be studied more elaborately by utilizing data sets with higher resolution and more information. 


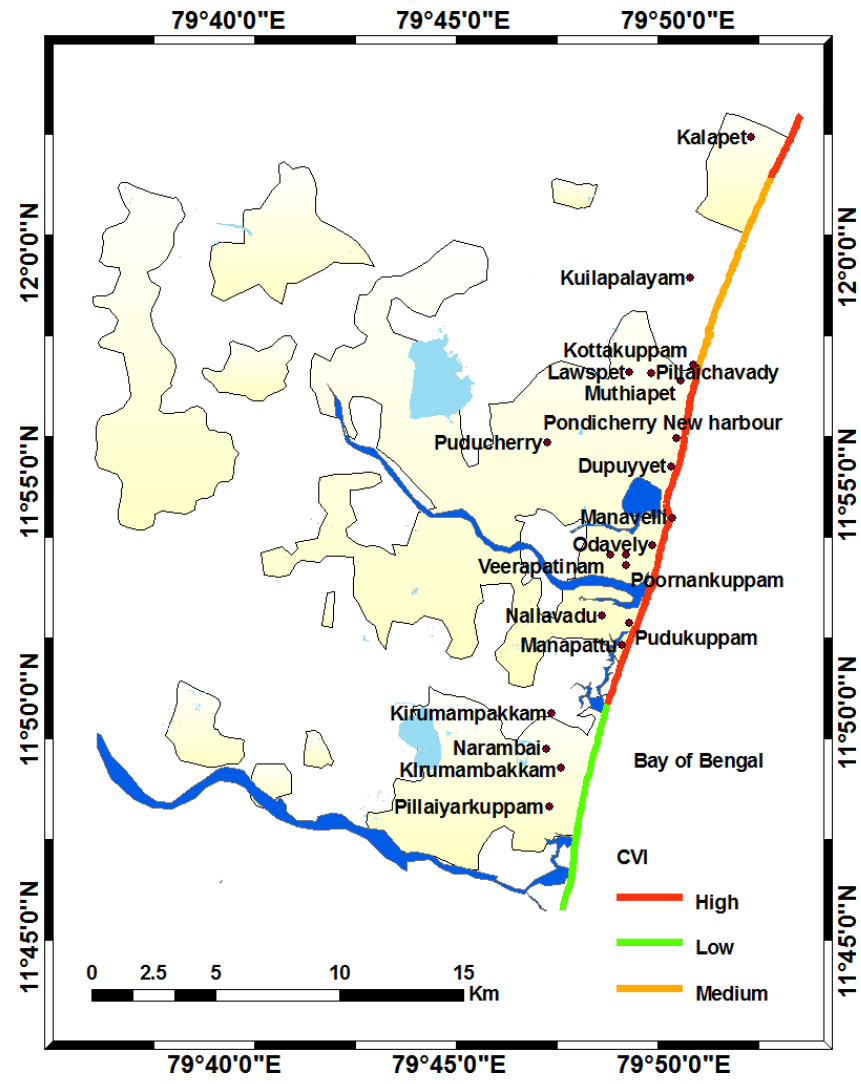

Fig. 13. Coastal vulnerability index map.

Table 10. Computation of consistency ratio (CR).

\begin{tabular}{lrr}
\hline Parameters & $\begin{array}{r}\text { Physical } \\
\text { variables }\end{array}$ & $\begin{array}{r}\text { Socio-economic } \\
\text { variables }\end{array}$ \\
\hline$\lambda \max$ & 7.68 & 4.24 \\
$n$ & 7.00 & 4.00 \\
$\mathrm{CI}$ & 0.11 & 0.08 \\
$\mathrm{RI}$ & 1.32 & 0.09 \\
$\mathrm{CR}$ & 0.09 & 0.09 \\
\hline
\end{tabular}

It is important to understand here that either singularly or collectively the physical and social indicators only represent the conceptualization of vulnerability as an exposure measure (Boruff et al., 2005). Thus, researchers should consider more spatially and temporally varying socio-economic data along with physical variables (e.g., sediment supply, coastal defenses, climatic, and oceanographic data) in their study. An assessment of vulnerability in each area based upon both groups of variables should be implemented for the purpose of designing policy and mitigation measures to increase their flexibility and specificity. Nevertheless, this analysis of PVI, SVI and CVI results can contribute to the better understanding of the variability and determinants of vulnerability for various regions.

\subsection{Uncertainty in the analysis}

The major drawback of multi-criteria analysis is the difficulty in quantifying the inaccuracies and uncertainties involved, however a qualitative analysis can be performed to enable better understanding. Table 11 lists the various uncertainties involved in the study and their significance. One of the major sources of uncertainty is the data. The vulnerability assessment includes data from several sources, which vary in scale, spatial and temporal resolutions. For example, while shoreline change analysis is taken in terms of the linear shoreline vectors, the slope data set considered is a raster. Further, although most of the data considered in the case of PVI is in the shoreline segment scale, the socio-economic data is at a district or sub-district level. In terms of temporal resolution, PVI involves both long and short term data, whereas CVI involves data of one year, thus the latter being a more static indicator of the condition at a point in time.

Another pertinent source of uncertainty can be attributed to the AHP ranking method. It is a difficult task to assign weights based on relative importance, especially in the case of higher order factors such as elevation or slope. Also determining the importance of factors like sea level, significant wave height and tidal range with single data values was a difficult choice. They were mostly made on the basis of drivers specific to the region as suggested in literature or as observed by the experts. Le Cozannet et al. (2013) in their study evaluated the sensitivity of AHP to two sea level scenarios and compared the associated maps. We have done a sensitivity analysis to check if alteration of ranking in the AHP tree alters the overall decision and vulnerability map. We have taken two conditions, first we have considered elevation the second most important parameter (Saaty's number 8) and geomorphology third (Saaty's number 7); second we have considered significant wave height the least important parameter (Saaty's number 1) and Tidal range the second least relevant parameter (Saaty's number 2). Table 11 describes a rough qualitative evaluation of uncertainty in the study (approach similar to Bell and Glade, 2004), and it is open for further refinement with the upcoming high quality data sets. A sensitivity analysis was done to check the influence of changes in weights in the AHP decision tree, the results of which are shown in Fig. 14. Further, we have compared the associated maps with our coastal vulnerability map (Fig. 14) and the available field information. In the first case, there is no change in the results obtained after changing the ranking of elevation and a similar map is produced after evaluating the AHP tree. For the second scenario, the $250 \mathrm{~m}$ extent of shoreline between Nallavadu and Kirumampakkam changed from high vulnerability class to medium vulnerability, the rest being the same. Also, these maps agree with the field knowledge of the most vulnerable regions. Thus, through this analysis it is concluded that there is little change in the result with the alteration of the weighting in the decision tree and hence 
Table 11. Qualitative estimation of uncertainties within the case study.

\begin{tabular}{|c|c|c|c|}
\hline Source of uncertainty & Uncertainty & Reason & Significance \\
\hline Data sets used for analysis & Medium-High & Varying spatial, temporal resolutions and scales & High \\
\hline $\begin{array}{l}\text { Processing of data set for each pa- } \\
\text { rameter, defining classes and rank- } \\
\text { ing }\end{array}$ & Low-Medium & $\begin{array}{l}\text { Better methods in terms of modeling etc are available } \\
\text { but have not been used here. Ranking based on literature } \\
\text { information and expert knowledge }\end{array}$ & Low-Medium \\
\hline $\begin{array}{l}\text { Defining the weighing criteria and } \\
\text { factors in AHP }\end{array}$ & Low & $\begin{array}{l}\text { Sensitivity analysis shows little influence of change in } \\
\text { weights and hence AHP is a good method for deciding } \\
\text { weights for vulnerability analysis. }\end{array}$ & Medium \\
\hline Validation of result & Low-Medium & $\begin{array}{l}\text { Validated with field surveys, expert judgment, and sen- } \\
\text { sitivity analysis. However, some subjectivity is intrinsi- } \\
\text { cally involved. }\end{array}$ & Medium \\
\hline
\end{tabular}

AHP-derived weights can be used for realistic vulnerability mapping.

\subsection{Advantages and disadvantages of the method considered}

The advantages of AHP have been discussed elaborately in previous sections. As seen from its application for the coastal vulnerability of Puducherry, it is evident that it is efficient in estimating the weights required for further processing of the indices. It is very difficult to develop common methodologies at country level; hence, regional vulnerability procedures should be established to study the vulnerabilities of different regions. AHP enables relative ranking of criteria and hence the order of parameters chosen can be flexibly altered based on the dominant conditions prevailing in a particular region. Thus, we think this approach can be used successfully for the assessment of coastal vulnerability of the various coastal regions of India and other parts of the world coastline.

It is also important to specify the disadvantages of this method, which is considerably different in the case of other vulnerability methodologies. Firstly, the hierarchical framework offers limited representation on a one-to-one basis, which does not take into account interaction between the parameters. Secondly, as stated earlier, lack of data or data inconsistencies can affect the overall study, which can be removed by incorporating more detailed data sets of considerable spatial and temporal resolutions. The third limitation arises due to the methodologies used in depicting the parameters; for example the use of NCEP/NCAR data for SWH analysis or the use of Wxtide for tidal analysis. Finally, this type of analysis mainly focuses on coastal threats as a whole rather than in the pretext of a specific event such as cyclones or sea level changes. Nevertheless, we believe AHP can still be used in such cases, but with more elaborate long-term data sets.

\subsection{Potential use of this method in disaster management}

This paper attempts to develop a robust methodology to aid policy-makers in coastal management projects. This kind of study can be used for both short- and long-term coastal planning. The inclusion of both physical and socio-economic gives an idea of multiple scenarios that can be used to devise better adaptive strategies. The assessment of vulnerability allows for a critical evaluation of the proposed adaptation strategies and if they are actually effective or rather detrimental. For instance, the shoreline change analysis performed in this study showing the accretion and erosion patterns along Puducherry throws light on how the placement of artificial hard structures has negatively affected the coastline. The results of these assessments are also very valuable for the regional stakeholders mainly involved in developmental activities along the coastal belts. As in the case of Puducherry, a major tourist destination, it is essential that the maps obtained from this analysis are considered before setting up new establishments. Finally, maps obtained from vulnerability studies prove to be very beneficial from the risk prevention point of view, as they estimate the degree to which the coastline is vulnerable during natural disasters.

\section{Conclusions}

The rising number of coastal disasters along the world's coastlines throws light on the need for better and more efficient methodologies for the assessment of coastal vulnerability. Here, relative physical-geological (geomorphology) and socio-economic parameters have been selected to understand the sensitivity of the coast of Puducherry to natural hazards. The study encourages the inclusion of socioeconomic parameters in vulnerability studies, and proposes the use of analytical hierarchical process (AHP) for deriving the weights for this assessment. Socio-economic factors are important, as the data related to these aspects vary across the study area since these parameters are associated with humans, land use, transportation, and cultural heritage and can 


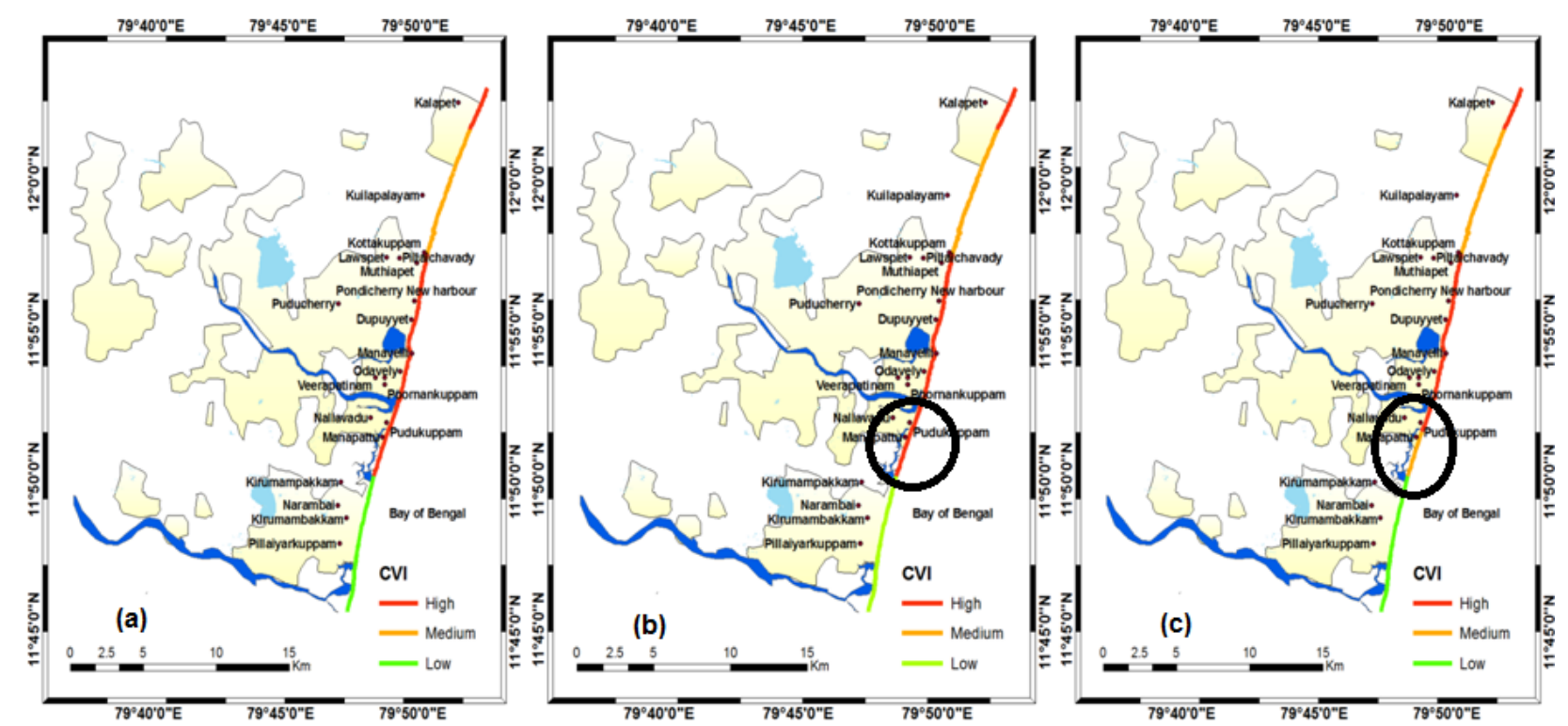

Fig. 14. Sensitivity analysis: Comparison of CVI maps with different weights - (a) Coastal Vulnerability Index Map (Saaty's Number for Geomorphology: 8, Regional Elevation: 7, Significant wave height: 2 and Tidal range: 1, (b) Coastal Vulnerability Index Map (Saaty's Number for Regional Elevation: 8, Geomorphology: 7, (c) Coastal Vulnerability Index Map (Saaty's Number for Tidal Range: 2, Significant wave height: 1).

hence prove to be essential in terms of the reaction of a particular area to a natural disaster. The analytical hierarchical process (AHP) proposed by Saaty (1977) is a popular approach to multi-criteria decision-making, which enables the experts to translate their subjective judgments into quantitative weights. Hence, it is more advantageous in the case of vulnerability assessment where there is a lack of a purely deterministic method owing to the huge data involved from different sources.

This paper presents an objective methodology to analyze and illustrate the vulnerability linked with various coastal hazards and can be used effectively by coastal managers and decision-makers to devise better coastal zone management plans as well as to ensure efficient mitigation measures to lessen the losses during disasters. Finally, in the social context, the vulnerability maps produced can be used as broad indicators of the susceptibility of the people living along the coastline to coastal hazards.

Acknowledgements. Authors thank the director of the NIO for permitting to carry out this work. They also acknowledge Vinod Kumar for providing the SWH values and Shree Vidya for the field photos. This is NIO contribution No 5515.

Edited by: P. Tarolli

Reviewed by: two anonymous referees

\section{References}

Abuodha, P. A. and Woodroffe, C. D.: International assessments of the vulnerability of the coastal zone to climate change, including an Australian perspective, Australian Greenhouse Office, Department of the Environment and Heritage, University of Wollongong, Faculty of Science Papers, Research Online, 75 pp., 2006.

Adger, W. N.: Approaches to Vulnerability to Climate Change, CSERGE Working Paper GEC, 96-05, Centre for Social and Economic Research on the Global Environment, University of East Anglia, Norwich, and University College London, 1996.

Allen, K.: Vulnerability reduction and the community-based approach, in: Natural Disasters and Development in a Globalising World, edited by: Pelling, M., Routledge (Taylor \& Francis), UK, Canada and USA, 170-184, 2003.

Bell, R. and Glade, T.: Quantitative risk analysis for landslides - Examples from Bíldudalur, NW-Iceland, Nat. Hazards Earth Syst. Sci., 4, 117-131, doi:10.5194/nhess-4-117-2004, 2004.

Bhatt, R., Macwan, J. E. M., Bhatt, D., and Patel, V.: Analytic Hierarchy Process Approach for Criteria Ranking of Sustainable Building Assessment: A Case Study, World Appl. Sci. J., 7, 881888, 2010.

Birkmann, J.: Measuring vulnerability to promote disaster-resilient societies: Conceptual frameworks and definitions, in: Measuring vulnerability to natural hazards, United Nations Univ. Press, Tokyo, 9-54, 2006.

Boruff, B. J., Emrich, C., and Cutter, S. L.: Erosion hazard vulnerability of US coastal counties, J. Coastal Res., 21, 932-942, 2005.

Bryan, B., Harvey, N., Belperio, T., and Bourman, B.: Distributed process modeling for regional assessment of coastal vulnerability to sea-level rise, Environ. Model. Assess., 6, 57-65, 2001.

Chang, H. K., Liou, J. C., and Chen, W. W.: Protection priority in the coastal environment using a hybrid ahp-topsis method 
on the Miaoli coast, Taiwan, J. Coast. Res., 28, 369-374, doi:10.2112/jcoastres-d-10-00092.1, 2012.

Cooper, J. A. G. and McKenna, J.: Social justice in coastal erosion management: The temporal and spatial dimensions, Geoforum, 39, 294-306, doi:10.1016/j.geoforum.2007.06.007, 2008.

Creel, L.: Ripple effects: Population and Coastal Regions, Population Reference Bureau, Washington DC, USA, 2003.

Diez, P. G., Perillo, G. M. E., Piccolo, M. C., and Beach, W. P.: Vulnerability to sea-level rise on the coast of the Buenos Aires province, J. Coastal Res., 23, 119-126, 2007.

Dinesh Kumar, P. K.: Potential Vulnerability Implications Of Sea Level Rise For The Coastal Zones Of Cochin, Southwest Coast Of India, Environ. Monit. Assess., 123, 333-344, 2006.

Dwarakish, G. S., Vinay, S. A., Natesan, U., Asano, T., Kakinuma, T., Venkataramana, K., Pai, B. J., and Babita, M. K.: Coastal vulnerability assessment of the future sea level rise in Udupi coastal zone of Karnataka state , west coast of India, Ocean Coast. Manage., 52, 467-478, doi:10.1016/j.ocecoaman.2009.07.007, 2009.

EC: Climate Change and the European Water Dimension A Report to the European Water Directors. EU Report No. 21553, European Commission-Joint Research Centre (Publisher), Ispra, Italy, 2005.

EEA: The changing faces of Europe's coastal areas, EEA Report No 6/2006, European Environment Agency, Copenhagen, 2006.

Füssel, H. M. and Klein, R. J. T.: Climate Change Vulnerability Assessments: An Evolution of Conceptual Thinking, Climatic Change, 75, 301-329, 2006.

Gornitz, V.: Global coastal hazards from future sea level rise, Palaeogeography, Palaeoclimatology, Palaeoecology, 89, 379398, doi:10.1016/0031-0182(91)90173-O, 1991.

Gornitz, V. and Kanciruk, P.: Assessment of global coastal hazards from sea-level rise, Proceedings of the 6th Symposium on Coastal and Ocean management, ASCE, Charleston, SC, 11-14 July, 1989.

Hanson, S., Nicholls, R., Ranger, N., Hallegatte, S., Corfee-Morlot, J., Herweijer, C., and Chateau, J.: A global ranking of port cities with high exposure to climate extremes, Climatic Change, 104, 89-111, doi:10.1007/s10584-010-9977-4, 2011.

IPCC: Summary for Policymakers, in: Climate Change 2007: The Physical Science Basis. Contribution of Working Group I to the Fourth Assessment Report of the Intergovernmental Panel on Climate Change, edited by: Solomon, S., Qin, D., Manning, M., Chen, Z., Marquis, M., Averyt, K. B., Tignor, M., and Miller, H. L., Cambridge University Press, Cambridge, United Kingdomand New York, NY, USA, 2007.

Jayakumar, S., Ilangovan, D., Naik, K. A., Gowthaman, R., Tirodkar, G., Naik, G. N., Ganesan, P., ManiMurali, R., Michael, G. S., Ramana, M. V., and Bhattacharya, G. C.: Run-up and inundation limits along southeast coast of India during the 26 December 2004 Indian Ocean tsunami, Curr. Sci., 88, 1741-1743, 2005.

Jones, R. and Boer, R.: Assessing current climate risks,in: Adaptation Policy Framework for Climate change: Developing strategies, policies and measures, UNDP, Cambridge University Press, Cambridge, UK, 91-117, 2004.

Ju, C. Y., Jia, Y. G., Shan, H. X., Tang, C. W., and Ma, W. J.: GISbased coastal area suitability assessment of geo-environmental factors in Laoshan district, Qingdao, Nat. Hazards Earth Syst. Sci., 12, 143-150, doi:10.5194/nhess-12-143-2012, 2012.
Karwel, K. and Ewiak, I.: Estimation of the accuracy of the SRTM terrain model on the area of Poland. In Proceedings of the XXI ISPRS Congress, 3-11, 2008

Kellndorfer, J., Walker, W., Pierce, L., Dobson, C., Fites, J. A., Hunsaker, C., Vona, J., and Clutter, M.: Vegetation height estimation from shuttle radar topography mission and national elevation datasets, Remote Sens. Environ., 93, 339-358, 2004.

Klein, R. J. T., Nicholls, R. J., and Thomall, F.: Resilience to natural hazards: How useful is this concept?, Environ. Hazards, 5, 3545, 2003

Kumar, A. A. and Kunte, P. D.: Coastal vulnerability assessment for Chennai, east coast of India using geospatial techniques, Nat. Hazards, 64, 853-872, doi:10.1007/s11069-012-0276-4, 2012.

Kumar, T. S., Mahendra, R. S., Nayak, S., Radhakrishnan, K., and Sahu, K. C.: Coastal Vulnerability Assessment for Orissa State, East Coast of India, J. Coastal Res., 263, 523-534, doi:10.2112/09-1186.1, 2010.

Le Cozannet, G., Garcin, M., Bulteau, T., Mirgon, C., Yates, M. L., Méndez, M., Baills, A., Idier, D., and Oliveros, C.: An AHPderived method for mapping the physical vulnerability of coastal areas at regional scales, Nat. Hazards Earth Syst. Sci., 13, 1209 1227, doi:10.5194/nhess-13-1209-2013, 2013.

Levermann, A., Clark, P. U., Marzeion, B., Milne, G. A., Pollard, D., Radic, V., and Robinson, A.: The multimillennial sea-level commitment of global warming, Proc. Natl. Acad. Sci. USA, 110, 13745-13750, doi:10.1073/pnas.1219414110, 2013.

Løvholt, F., Kaiser, G., Glimsdal, S., Scheele, L., Harbitz, C. B., and Pedersen, G.: Modeling propagation and inundation of the 11 March 2011 Tohoku tsunami, Nat. Hazards Earth Syst. Sci., 12, 1017-1028, doi:10.5194/nhess-12-1017-2012, 2012.

Luers, A. L., Lobell, D. B., Sklar, L. S., Addams, C. L., and Matson. P. A.: A method for quantifying vulnerability, applied to the Yaqui Valley, Mexico, Global Environ. Chang., 13, 255-267, 2003.

Mahendra, R. S., Mohanty, P. C., Bisoyi, H., Kumar, T. S., and Nayak, S.: Assessment and management of coastal multi-hazard vulnerability along the Cuddalore-Villupuram, east coast of India using geospatial techniques, Ocean Coast. Manage., 54, 302311, doi:10.1016/j.ocecoaman.2010.12.008, 2011.

Mani Murali, R., Shrivastava, D., and Vethamony, P.: Monitoring shoreline environment of Paradip, east coast of India using remote sensing, Curr. Sci., 97, 79-84, 2009.

Mani Murali, R., Vethamony, P., Saran, A. K., and JayaKumar, S. Change detection studies in coastal zone features of Goa, India by remote sensing, Curr. Sci., 91, 816-820, 2006.

McFadden, L., Penning-Rowsell, E., and Nicholls, R. J.: Setting the Parameters: A Framework for Developing Cross-Cutting Perspectives of Vulnerability for Coastal Zone Management, in: Managing Coastal Vulnerability, edited by: McFadden, L., Nicholls, R. J., and Penning-Rowsell, E., Oxford, UK, Elsevier, 262 pp., 2007.

McLaughlin, S., Mckenna, J., and Cooper, J. A. G.: Socio-economic data in coastal vulnerability indices: constraints and opportunities, J. Coastal Res., 36, 487-497, 2002.

Nageswara Rao, K., Subraelu, P., Venkateswara Rao, T., Hema Malini, B., Ratheesh, R., Bhattacharya, S., and Rajawat, A. S.: Sealevel rise and coastal vulnerability: an assessment of Andhra Pradesh coast, India through remote sensing and GIS, J. Coast. Conserv., 12, 195-207, doi:10.1007/s11852-009-0042-2, 2008. 
Nicholls, R. J. and Cazenave, A.: Sea-level rise and its impact on coastal zones, Science (New York, NY), 328, 1517-1520, doi:10.1126/science.1185782, 2010.

O’Connor, M. C., Lymbery, G., Cooper, J. A. G., Gault, J., and Mckenna, J.: Practice versus policy-led coastal defence management, Mar. Policy, 33, 923-929, 2009.

Ozyurt, G., Ergin, A., and Baykal, C: Coastal vulnerability assessment to sea level rise integrated with analytical hierarchy process, Coast. Eng. Proc., 1, doi:10.9753/icce.v32.management.6, 2012.

Peltier, W. R.: Global Isostatic Adjustment and Modern Instrumental Records of Relative Sea Level History, in: Sea Level Rise History and Consequences, edited by: Douglas, B. C., Kearney, M. S., and Leatherman, S. P., Academic Press, 65-95, 2001.

Peltier, W. R.: Global Isostacy and the Surface of the Ice-Age Earth: The ICE-5G (VM2) model and GRACE, Ann. Rev. Earth Planet. Sci., 32, 111-149, 2004.

Pendleton, E. A., Thieler, E. R., and Williams, S. J.: Coastal Vulnerability Assessment of Channel Islands National Park (CHIS) to Sea-Level Rise, USGS, Woods Hole, Massachusetts, United States Geological Survey (USGS), Reston, VA, Open-File Report, 2005-1057, 2005.

Phukon, P., Chetia, D., and Das, P.: Landslide Susceptibility Assessment in the Guwahati City, Assam using Analytic Hierarchy Process (AHP) and Geographic Information System (GIS), Int. J. Comput. Appl. Eng. Sci., 2, 1-6, 2012.

Pye, K. and Blott, S. J.: Coastal processes and morphological change in the Dunwich-Sizewell area, Suffolk, UK, J. Coast. Res., 22, 453-473, doi:10.2112/05-0603.1, 2006.

Rahman, M. R., Shi, Z. H., and Chongfa, C.: Soil erosion hazard evaluation-an integrated use of remote sensing, GIS and statistical approaches with biophysical parameters towards management strategies, Ecol. Model., 220, 1724-1734, doi:10.1016/j.ecolmodel.2009.04.004, 2009.

Ramesh, R., Purvaja, R., and Senthil Vel, A.: National Assessment of Shoreline Change: Puducherry Coast, NCSCM/MoEF Report 2011-01, Chennai, India, 57 pp., 2011.

Roger, J., Dudon, B., and Zahibo, N.: Tsunami hazard assessment of Guadeloupe Island (F.W.I.) related to a megathrust rupture on the Lesser Antilles subduction interface, Nat. Hazards Earth Syst. Sci., 13, 1169-1183, doi:10.5194/nhess-13-1169-2013, 2013.

Romieu, E., Welle, T., Schneiderbauer, S., Pelling, M., and Vinchon, C.: Vulnerability assessment within climate change and natural hazard contexts: revealing gaps and synergies through coastal applications, Sustain Sci., 5, 159-170, doi:10.1007/s11625-0100112-2, 2010.

Saaty, T. L.: A scaling method for priorities in hierarchical structures, J. Math. Psychol., 15, 234-281, 1977.

Saaty, T. L. and Vargas, L. G.: Prediction, Projection and Forecasting: Applications of the Analytic Hierarchy Process in Economics, Finance, Politics, Games and Sports, Kluwer Academic Publishers, Boston, 1991.

Sindhu, B., Suresh, I., Unnikrishnan, A. S., Bhatkar, N. V, Neetu, S., and Michael, G. S.: Improved bathymetric datasets for the shallow water, J. Earth Syst. Sci., 3, 261-274, 2007.

Sinha, R., Bapalu, G. V., Singh, L. K., and Rath, B.: Flood Risk analysis in the Kosi River Basin, North Bihar using Multi parametric approach of Analytical Hierarchical Process (AHP), J. Indian Soc. Remote Sens., 36, 335-349, 2008.
Strohecker, K.: World sea levels to rise $1.5 \mathrm{~m}$ by 2100 - scientists, an Environmental News Network and Reuters publication, available at: http://www.enn.com/wildlife/article/34702, last access: 24 July 2008.

Szlafsztien, C. F.: Climate change, Sea-level rise and Coastal Natural Hazard: A GIS-Based Vulnerability Assessment, State of Pará, Brazil, J. Coast. Conserv., 11, 53-66, 2005.

Taubenböck, H., Post, J., Roth, A., Zosseder, K., Strunz, G., and Dech, S.: A conceptual vulnerability and risk framework as outline to identify capabilities of remote sensing, Nat. Hazards Earth Syst. Sci., 8, 409-420, doi:10.5194/nhess-8-409-2008, 2008.

Thieler, E. R. and Hammer-Klose, E. S.: National Assessment of Coastal Vulnerability to Sea-Level Rise: Preliminary Results for the US Atlantic coast, USGS, Woods Hole, Massachusetts, United States Geological Survey (USGS), Reston, VA, Open File Report, 99-593, available at: http://pubs.usgs.gov/of/1999/ of99-593/index.html (last access: 30 August 2008), 1999.

Thieler, E. R. and Hammer-Klose, E. S.: National Assessment of Coastal Vulnerability to Sea-Level Rise: Preliminary Results for the US Pacific Coast, Woods Hole, Massachusetts, United States Geological Survey (USGS), Reston, VA, Open File Report, 00178, 1, 2000.

Torresan, S., Critto, A., Rizzi, J., and Marcomini, A.: Assessment of coastal vulnerability to climate change hazards at the regional scale: the case study of the North Adriatic Sea, Nat. Hazards Earth Syst. Sci., 12, 2347-2368, doi:10.5194/nhess-12-23472012, 2012.

Turner, B. L., Kasperson, R. E., Matson, P. A., McCarthy, J. J., Corell, R. W., Christensen, L., Eckley, N., Kasperson, J. X., Luers, A., Martello, M. L., Polsky, C., Pulsipher, A., and Schiller, A.: A framework for vulnerability analysis in sustainability science, Proc. Natl. Acad. Sci. USA, 100, 8074-8079, doi:10.1073/pnas.1231335100, 2003.

Unnikrishnan, A. S. and Shankar, D.: Are sea-level-rise trends along the coasts of the north Indian Ocean consistent with global estimates??, Glob. Planet Chang., 57, 301-307 doi:10.1016/j.gloplacha.2006.11.029, 2007.

Unnikrishnan, A. S., Kumar, K. R., Fernandes, S. E., Michael, G. S., and Patwardhan, S. K.: Sea level changes along the Indian coast: observations and projections, Curr. Sci. India, 90, 362368, 2006.

USGS: The Digital Shoreline Analysis System (DSAS) version 3.0, an Arc-GIS Extension for Calculating Histrionic Shoreline Change, Open-File Report 2005-130, 2005.

USGS: Shuttle Radar Topography Mission (SRTM) 3 Arc Second (90 meter) - Description, available at: http://seamless.usgs. gov/website/seamless/products/srtm3arc.asp (last access: February 2013), 2006.

Vethamony, P., Sudheesh, K., Rupali, S. P., Babu, M. T., Jayakumar, S., Saran, A. K., Basu, S. K., Kumar, R., and Sarkar, A.: Wave modeling for the north Indian Ocean using MSMR analysed winds, Int. J. Remote Sens., 27, 3767-3780, doi:10.1080/01431160600675820, 2006.

Vittal Hegde, A. and Radhakrishnan Reju, V.: Development of Coastal Vulnerability Index for Mangalore Coast, India, J. Coastal Res., 235, 1106-1111, doi:10.2112/04-0259.1, 2007.

Willroth, P., Massmann, F., Wehrhahn, R., and Revilla Diez, J.: Socio-economic vulnerability of coastal communities in southern Thailand: the development of adaptation strategies, Nat. Hazards 
Earth Syst. Sci., 12, 2647-2658, doi:10.5194/nhess-12-26472012, 2012.

Woodworth, P. L. and Player, R.: The Permanent Service for Mean Sea Level: An update to the 21st century, J. Coastal Res., 19, 287-295, 2003

Yin, J., Yin, Z., Wang, J., and Xu, S.: National assessment of coastal vulnerability to sea-level rise for the Chinese coast, J. Coast. Conservation, 16, 123-133, doi:10.1007/s11852-0120180-9, 2012.
Zielinski, R. and Chmiel, J.: Vertical accuracy assessment of SRTM C-band DEM data for different terrain characteristics, New Developments and Challenges in Remote Sensing, edited by: Bochenek, Z., Millpress, Rotterdam, ISBN 978-90-5966-053-3, 2007. 